Research Article

\title{
Impact Analysis of Intermediate Heat Carrier on Heat Transfer in Furnace
}

\author{
Cheng Li $\mathbb{D}^{1,2}$ Wei-Jun Zhang $\mathbb{D}^{1,2} \mathrm{Zhi} \mathrm{Yi}^{1,2} \mathrm{Na} \mathrm{Li}{ }^{1,2}$ and $\mathrm{Kai}_{\mathrm{Li}}{ }^{1,2}$ \\ ${ }^{1}$ Furnace Research Institute, Northeastern University, Shenyang, Liaoning 110819, China \\ ${ }^{2}$ School of Metallurgy, Northeastern University, Shenyang, Liaoning 110819, China \\ Correspondence should be addressed to Wei-Jun Zhang; zhangwj@smm.neu.edu.cn
}

Received 26 September 2019; Accepted 16 January 2020; Published 10 March 2020

Academic Editor: Alessandro Mauro

Copyright (c) 2020 Cheng Li et al. This is an open access article distributed under the Creative Commons Attribution License, which permits unrestricted use, distribution, and reproduction in any medium, provided the original work is properly cited.

Intermediate heat carriers have been applied in engineering as enhanced heat transfer elements, but their theoretical analysis still needs to be improved. Therefore, an intermediate heat carrier is added to establish the quaternary model of the furnace gas under nongray radiation characteristics. Based on this model, an analytical expression of heat flux on the surface of the billet is derived. General rule of the impact of intermediate heat carrier on the thermal efficiency in the furnace can be properly derived by analytical calculation from a theoretical point of view. The results show that the longer the length of the intermediate heat carrier located at the top of the furnace, the greater the heat exchange capacity on the surface of the billet. Meanwhile, when the intermediate heat carrier is located in the center of the furnace top, the billet gets higher heat flux; the closer to both sides, the lower the heat flux. In addition, the influence that the surface emissivity of the intermediate heat carrier has on the heat transfer of the billet surface is related to the values of $\varepsilon_{\mathrm{g}}$ and $\alpha_{\mathrm{gw}}$. Comparison with previous literature shows that adding intermediate heat carrier can improve the heat exchange capacity of billet.

\section{Introduction}

In order to reduce carbon dioxide emissions from iron and steel enterprises and improve the thermal efficiency of heating furnace, increasing radiation from furnace wall is an effective method that needs more attention [1]. The thermal efficiency of heating furnace depends on many factors, among which, the appropriate shape of furnace can maximize the radiation of furnace wall, so that the thermal efficiency of furnace can be improved [2]. Therefore, scholars have proposed the concept of blackbody technology. The socalled blackbody technology refers to the industrial standard blackbody element, also called the intermediate heat carrier in furnace, which integrates three functions of "enlarging furnace area, increasing furnace emissivity, and increasing irradiance" by using certain materials and processing technology according to the blackbody theory of infrared physics. Numerous intermediate heat carriers were installed in the proper position of the inner furnace wall to enable the disordered and diffuse heat rays in the furnace to directly radiate to the heated workpiece, greatly improving the arrival rate of heat rays, thus effectively improving the thermal efficiency of heating furnace and realizing the purpose of energy-saving. Intermediate heat carrier was suspended on the inner surface of the furnace wall; meanwhile, the specific surface area of the furnace wall was also increased. According to Тимофеeв formula, by increasing the area of furnace wall, the angle coefficient of furnace wall against heated metal can be reduced and system emissivity can be increased, thus playing a positive role in enhancing heat transfer in the furnace.

Due to the complexity of the radiation situation in the furnace, the previous research on the heating furnace with intermediate heat carriers was carried out through experiments, so its theoretical analysis still needs to be improved. As a result, there is no theoretical basis for the optimum structure, surface radiation characteristics, and installation position of the intermediate radiator, and no clear method can be found to regulate the temperature through the intermediate radiator. By theoretical calculation, the general rule of radiation heat transfer in the furnace can be obtained without consuming substantial experimental costs. 
The development of industry needs to consume a lot of energy. For example, the energy for metal heating and glass melting mainly comes from the combustion of fossil fuels $[3,4]$. In the next many decades, still $80 \%$ of the global energy will be generated by burning fossil fuels, and it will also be the main source of carbon dioxide emissions [5-7]. In industrial production, energy consumption is increasing, so it is inevitable to increase energy efficiency $[8,9]$. Continuous heating furnace is important heating equipment of the rolling or heat treatment process, which is used to heat billet so that the temperature of the billet can reach recrystallization temperature $[10,11]$. In iron and steel enterprises, energy consumption of a rolling heating furnace is the second largest [12] after iron-making. Therefore, it is of great significance to improve the efficiency of the heating furnace for saving fossil resources and reduction of the environmental pollution caused by the excessive emission of carbon dioxide.

Energy-saving effect of the heating furnace can be effectively improved by enhancing the heat transfer in the furnace. Generally speaking, the radiation heat transfer system in the heating furnace can be considered as a ternary system [13] composed of furnace gas, furnace wall, and heated materials. Radiation heat transfer plays a dominant role in heat transfer in furnace. About $90.3 \%$ of heat flux on billet surface comes from radiation heat transfer [14-16], which depends on the temperature and emissivity of the heat transfer surface and their geometric structure and the properties of the surrounding gases [1]. According to the Stefan-Boltzmann law [17-22], the radiation heat exchange capacity is proportional to the fourth power of temperature difference, so the difference of temperature among surfaces has a significant impact on thermal radiation. In order to explore the impact rule of radiation heat transfer in heating furnace, scholars around the world carried out modeling research [23-27]. By using the analytic method, Тимофеев deduced the calculating method of differential heat flux of the heated workpiece in the furnace, also the basic formula of radiation heat exchange in furnace till now, when the furnace gas is a gray body and the furnace wall is regarded as the zero heat flux surface of radiation. On this basis, Yi et al. [1] extended Тимофеев's analysis to remove the assumption that the furnace wall is a reradiating surface, improving the accuracy of the original formula, meanwhile investigating the impact of emissivity variation of furnace wall on the heat flux of billet surface.

In a ternary system, the furnace wall is designed to reflect (or reradiate) the energy radiated by furnace gas to material [1]. The radiation heat flux of wall plays a vital role on heat transfer in a furnace [28]. Therefore, scholars have done a lot of research on the impact of furnace wall on the radiation of billet. In terms of the shape of furnace, through modeling study, García and Amell [28] found that the larger the furnace, the lower the wall radiation to the billet; the higher temperature of the furnace, the higher the radiation emitted from the furnace wall and the lower the absorption of flue gas, enabling more wall radiation to reach the billet. The results are consistent with those of Emadi et al. [14]. By calculating the radiation exchange area, Chapman et al. [29] had verified that the furnace efficiency is reduced to a certain extent if the furnace wall area is increased by increasing the internal furnace space. This phenomenon can be explained from two aspects. Firstly, with the increase of combustion space, the gas temperature in furnace decreases, resulting in the decrease of convection and radiation flux from gas to billet and making the heat flux tend to decrease slightly. Secondly, the increase of furnace space leads to the increase of heat flux loss from the furnace wall to the external environment. Because the emissivity of the furnace wall has a significant impact on the radiation heat transfer process [30], some scholars have also studied the emissivity of the furnace wall surface. Dan et al. [31] et al has developed a new type of heating furnace coating with emissivity greater than 0.9 and thickness about $200 \mu \mathrm{m}$. Both the heating and cooling speed of the heating furnace with coating were improved by experiment. The temperature in the furnace was increased by $30^{\circ} \mathrm{C}$, and the fuel was saved by about $10 \%$. Hellander [32] applied ceramic coating on the wall of heating furnace, which greatly increased the emissivity of the wall, reduced the energy consumption of heating furnace by $15 \% \sim 30 \%$, and increased the service life by $2 \sim 5$ times.

On the basis of the heating furnace with nongray radiation characteristics of furnace gas established by $\mathrm{Yi}$ et al. [1], an intermediate heat carrier was added to the furnace, and a mathematical analytic formula of heat exchange capacity on the surface of billet was derived. Based on this mathematical analytic formula, the impact of different parameters on heat transfer in the furnace was analyzed.

\section{Derivation of Mathematical Expression for Surface Heat Flux of Billet}

2.1. Modeling. Due to the complexity of the heating process in the furnace, in order to obtain the analytical expression of the heat transfer process in the furnace with an intermediate heat carrier, the following simplifications should be made:

(1) The radiation heat transfer between the model sections was ignored, and it was considered that the radiation heat transfer occurs only inside each model section.

(2) The temperature distribution along the furnace width is assumed to be uniform in each model section.

(3) The impact of factors, such as oxidation burning loss, on heat transfer during the heating process is neglected.

(4) Both the furnace wall and billet is regarded as diffuse gray bodies, while the furnace gas has nongray characteristics.

(5) Because of the high temperature in the furnace, radiation is the main form of heat transfer in the furnace. In this study, the convective heat exchange between the furnace gas and the billet as well as that between the furnace gas and the furnace wall are 
neglected. For the coupled calculation of radiation and convective heat transfer, more details can be found in references [33-37].

On this basis, a one-zone quaternary radiation heat transfer model was established. Quaternary radiation heat transfer model is a simplified model of zonal method model, each zone of which is composed of furnace gas, intermediate heat carrier, heated billet, and furnace wall (furnace wall and furnace top). There is no radiation heat exchange in the length direction of furnace and the temperature is uniform along the width direction of furnace, so the section perpendicular to the length direction of furnace was taken for the analysis of radiation heat transfer, as shown in Figure 1.

In this study, the temperature of billet and furnace gas was given, so that the energy equation of furnace gas can be disregarded; thus, the calculation [38-40] can be simplified. Because the analytical analysis was only made for the surface heat exchange capacity of billet with or without intermediate heat carrier, the model adopted in this article introduced only one intermediate heat carrier to simplify the calculation and obtain a general rule. Meanwhile, the situation of different sections was simulated by changing the surface temperature of furnace gas and billet. The absorptivity of furnace gas to furnace wall and billet can be distinguished and expressed, respectively, as $\alpha_{g s}$ and $\alpha_{g w}$. The values of emissivity and absorptivity of flue gas can be calculated by Leckner correlations [41].

\subsection{Exchange Area with an Intermediate Heat Carrier.}

The flue gas in the furnace was assumed to be isothermal with uniform density. Therefore, the zonal method was adopted, and heat flux variation $[42,43]$ in the furnace was calculated by solving the direct exchange area.

Figure 2 is a simplified two-dimensional diagram of a quaternary radiation system with an intermediate heat carrier, where $l$ represents the length of intermediate heat carrier, $d$ represents the half length of billet, and $h$ represents the height of furnace wall.

According to the given size of the heating furnace, it can be obtained that

$$
\begin{aligned}
F_{c} & =2 l, \\
F_{w} & =2(h+d), \\
F_{s} & =2 d .
\end{aligned}
$$

According to the geometric shape shown in Figure 1, it can be obtained that

$$
X_{s, c}=\frac{l+\sqrt{(h-l)^{2}+d^{2}}-\sqrt{h^{2}+d^{2}}}{2 d} .
$$

According to the integrity of the angle factor, it can be obtained that

$$
X_{s, w}=1-X_{w, s} .
$$

According to the relativity of the angle factor, it can be obtained that

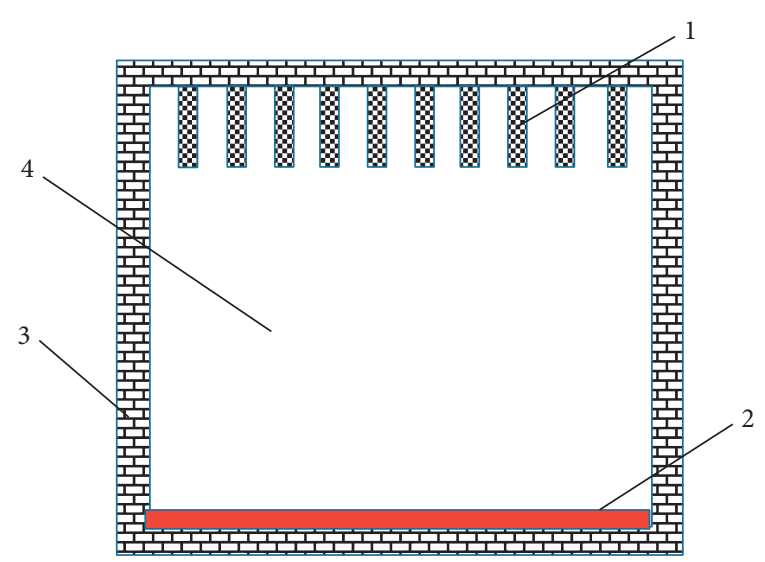

FIGURE 1: Section diagram of heating furnace with intermediate heat carrier. 1. Intermediate heat carrier. 2. Billet. 3. Furnace wall. 4. Furnace gas.

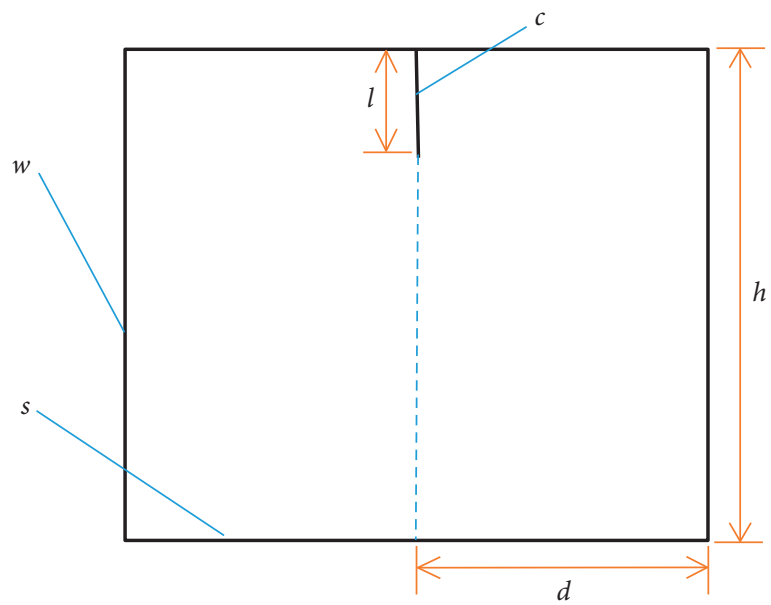

Figure 2: Two-dimensional diagram of furnace with intermediate heat carrier.

$$
X_{w, s}=\frac{F_{s}}{F_{w}} X_{s, w}=\frac{2 d}{3 h}\left[1-\frac{l+\sqrt{(h-l)^{2}+d^{2}}-\sqrt{h^{2}+d^{2}}}{2 d}\right] .
$$

Similarly, according to the relativity and integrity of the angular coefficient, it can be obtained that

$$
X_{w, c}=\frac{l}{2 d+2 h}\left[1-\frac{d}{l} \frac{l+\sqrt{(h-l)^{2}+d^{2}}-\sqrt{h^{2}+d^{2}}}{2 d}\right] .
$$

By substituting the angular coefficient and the area of each part in the furnace into the calculation of the radiation exchange area [38], the expression of surface heat flux of billet can be obtained.

2.3. Solution of Exchange Area. The calculation of the direct exchange area is a main step in the zonal method. In this 
study, due to the uniform and equal surface temperature distribution of gas, furnace wall, and billet, the direct exchange area was calculated as follows.

When gas $g$ is a radiation source,

$$
\begin{aligned}
{ }_{g} g s & =F_{s} \varepsilon_{g}=F_{s} \alpha_{g g}={ }_{g} s g, \\
{ }_{g} g w & =F_{w} \varepsilon_{g}={ }_{g} w g, \\
{ }_{g} g c & =F_{c} \varepsilon_{g}={ }_{g} c g, \\
{ }_{g} w s & =F_{w} X_{w s}\left(1-\varepsilon_{g}\right)={ }_{g} s w, \\
{ }_{g} w c & =F_{w} X_{w c}\left(1-\varepsilon_{g}\right)={ }_{g} c w, \\
g^{s c} & =F_{s} X_{s c}\left(1-\varepsilon_{g}\right)={ }_{g} c s, \\
{ }_{g} w w & =F_{w}\left(1-\varepsilon_{g}\right)\left(1-X_{w s}-X_{w c}\right) .
\end{aligned}
$$

When billet $s$ is the only radiation source,

$$
\begin{aligned}
{ }_{s} g s & =F_{s} \alpha_{g s}={ }_{s} s g, \\
{ }_{s} g w & =F_{w} \alpha_{g s}={ }_{s} w g, \\
{ }_{s} g c & =F_{c} \alpha_{g s}={ }_{s} c g, \\
{ }_{s} w s & =F_{w} X_{w s}\left(1-\alpha_{g c}\right)={ }_{s} s w, \\
{ }_{s} w c & =F_{w} X_{w c}\left(1-\alpha_{g s}\right)={ }_{s} c w, \\
{ }_{s} s c & =F_{s} X_{s c}\left(1-\alpha_{g s}\right)={ }_{s} c s, \\
{ }_{s} w w & =F_{w}\left(1-\alpha_{g s}\right)\left(1-X_{w s}-X_{w c}\right) .
\end{aligned}
$$

When furnace wall $w$ is the only radiation source,

$$
\begin{aligned}
{ }_{w} g s & =F_{s} \alpha_{g w}={ }_{w} s g, \\
{ }_{w} g w & =F_{w} \alpha_{g w}={ }_{w} w g, \\
{ }_{w} g c & =F_{c} \alpha_{g w}={ }_{w} c g, \\
{ }_{w} w c & =F_{w} X_{w c}\left(1-\alpha_{g w}\right)={ }_{w} c w, \\
{ }_{w} w s & =F_{w} X_{w s}\left(1-\alpha_{g w}\right)={ }_{w} s w, \\
{ }_{w} s c & =F_{s} X_{s c}\left(1-\alpha_{g w}\right)={ }_{w} c s, \\
{ }_{w} w w & =F_{w}\left(1-\alpha_{g w}\right)\left(1-X_{w s}-X_{w c}\right) .
\end{aligned}
$$

When the intermediate heat carrier $c$ is the only radiation source,

$$
\begin{aligned}
{ }_{c} g s & =F_{s} \alpha_{g c}={ }_{c} s g, \\
{ }_{c} g w & =F_{w} \alpha_{g c}={ }_{c} w g, \\
{ }_{c} g c & =F_{c} \alpha_{g c}={ }_{c} c g, \\
{ }_{c} w s & =F_{w} X_{w s}\left(1-\alpha_{g c}\right)={ }_{c} s w, \\
{ }_{c} w c & =F_{w} X_{w c}\left(1-\alpha_{g c}\right)={ }_{c} c w, \\
{ }_{c} s c & =F_{s} X_{s c}\left(1-\alpha_{g c}\right)={ }_{c} c s, \\
{ }_{c} w w & =F_{w}\left(1-\alpha_{g c}\right)\left(1-X_{w s}-X_{w c}\right) .
\end{aligned}
$$

Next, the reflected heat flux density [44] was calculated

$$
\begin{aligned}
& \left(\begin{array}{ccc}
-\frac{F_{s}}{\rho_{S}} & { }_{s} w s & { }_{s} c s \\
{ }_{s} s w & { }_{s} w w-\frac{F_{w}}{\rho_{w}} & \\
& & \\
& & \\
{ }_{s} s c & { }_{s} w c & -\frac{F_{c}}{\rho_{c}}
\end{array}\right)\left(\begin{array}{c}
{ }_{s} R_{s} \\
{ }_{s} R_{w} \\
{ }_{s} R_{c}
\end{array}\right)=\left(\begin{array}{c}
0 \\
-{ }_{s} s w \cdot \varepsilon_{s} \\
-{ }_{s} s c \cdot \varepsilon_{s}
\end{array}\right), \\
& \left(\begin{array}{ccc}
-\frac{F_{s}}{\rho_{S}} & { }_{w} w s & { }_{w} c s \\
{ } s w & { }_{w} w w-\frac{F_{w}}{\rho_{w}} & \\
& & \\
& & \\
{ }^{s c} & { }_{w} w c & -\frac{F_{c}}{\rho_{c}}
\end{array}\right)\left(\begin{array}{c}
{ }_{w} R_{s} \\
{ }_{w} R_{w} \\
{ }_{w} R_{c}
\end{array}\right)=\left(\begin{array}{c}
{ }_{w} w s \cdot \varepsilon_{w} \\
-{ }_{w} w w \cdot \varepsilon_{w} \\
-{ }_{w} w c \cdot \varepsilon_{w}
\end{array}\right), \\
& \left(\begin{array}{ccc}
-\frac{F_{s}}{\rho_{S}} & { }_{c} w s & { }_{c} c s \\
{ }^{s} s w & { }_{c} w w-\frac{F_{w}}{\rho_{w}}{ }_{c} c w \\
{ }_{c} s c & { }_{c} w c & -\frac{F_{c}}{\rho_{c}}
\end{array}\right)\left(\begin{array}{c}
{ }^{c} R_{s} \\
{ }_{c} R_{w} \\
{ }_{c} R_{c}
\end{array}\right)=\left(\begin{array}{c}
{ }_{c} c s \cdot \varepsilon_{c} \\
-{ }_{c} c w \cdot \varepsilon_{c} \\
0
\end{array}\right), \\
& \left(\begin{array}{ccc}
-\frac{F_{s}}{\rho_{S}} & { }_{g} w s & { }_{g} c s \\
g s w & g w w-\frac{F_{w}}{\rho_{w}} & \\
g & & \\
g^{s c} & { }_{g} w c & -\frac{F_{c}}{\rho_{c}}
\end{array}\right)\left(\begin{array}{c}
g^{R_{s}} \\
g^{R_{w}} \\
{ }_{g} R_{c}
\end{array}\right)=\left(\begin{array}{c}
{ }_{g} g s \\
-{ }_{g} g w \\
-{ }_{g} g c
\end{array}\right) .
\end{aligned}
$$

The calculation formulas of total exchange area $G S, G W$, $G C, S W, S C, W S, W C, C W, C S, S S, W W, C C, S G, W G$, and $C G$ can be obtained. It has been proved that the radiation total exchange area derived in this article satisfies the integrity condition; thus, the correctness of this derivation can be verified.

2.4. Expression of Surface Heat Flux on Billet. When the furnace environment is in a steady state, the energy equation of the inner surface of the furnace wall is as follows:

$$
Q_{e}=\sigma\left(G W T_{g}^{4}-W G T_{w}^{4}+S W T_{s}^{4}-W S T_{w}^{4}+C W T_{c}^{4}-W C T_{w}^{4}\right) .
$$

After arrangement, the fourth-power formula of furnace wall temperature can be obtained: 


$$
T_{w}^{4}=\frac{G W T_{g}^{4}+S W T_{s}^{4}+C W T_{c}^{4}-\left(Q_{e} / \sigma\right)}{W G+W S+W C} .
$$

Because the added intermediate heat carrier was actually used as the expansion surface of the furnace wall, the temperature of the intermediate heat carrier can be set to be the same as that of the furnace wall:

$$
T_{c}=T_{w} .
$$

By substituting it into the above equation, it can be obtained that

$$
T_{w}=\sqrt[4]{\frac{G W T_{g}+S W T_{s}-\left(Q_{e} / \sigma\right)}{W G+W S+W C-C W}} .
$$

Similarly, the energy equation of the billet surface can be expressed as follows:

$$
Q_{s}=\sigma\left(G S T_{g}^{4}-S G T_{s}^{4}+W S T_{w}^{4}-S W T_{s}^{4}+C S T_{c}^{4}-S C T_{s}^{4}\right) .
$$

2.5. Model Validation. In this article, the expression of heat flux on the surface of billet was calculated and obtained under the condition of nongray furnace gas, and there was an intermediate heat carrier on the top of the furnace. When the nongray characteristic of the furnace gas is not taken into account, that is, the length of the intermediate heat carrier $l$ is 0 , and the heat dissipation of the furnace wall is neglected, the formula is degenerated as

$$
Q_{e}=F_{s} \sigma \frac{\varepsilon_{g} \varepsilon_{s}\left[1+\left(F_{s} / F_{w}\right)\left(1-\varepsilon_{g}\right)\right]}{\varepsilon_{g}+\left(F_{s} / F_{w}\right)\left(1-\varepsilon_{g}\right)\left[\varepsilon_{s}+\varepsilon_{g}\left(1-\varepsilon_{s}\right)\right]}\left(T_{g}^{4}-T_{s}^{4}\right)
$$

This formula is the Тимофеeв formula which is an important analytical formula for studying the thermal process of a furnace and also the basic formula for analytic calculation of furnace by scholars. Thus, the correctness of the formula derived from this study can also be proved from this perspective.

Next, by using computer programming calculation, the impact on heat flux in furnace with intermediate heat carrier can be discussed.

\section{Result Analysis}

As mentioned above, the impact of intermediate heat carrier on theoretical analysis of surface heat exchange capacity of billet is unknown yet. Therefore, the length, position, and surface emissivity of the intermediate heat carrier are studied, and the impact of the intermediate heat carrier on the enhancement of heat transfer in the furnace is discussed in this article. The size of the furnace is set to $h=1 \mathrm{~m}$ and $d=2.5 \mathrm{~m}$.

The variation of heat exchange capacity of billet with the length of intermediate heat carrier at different temperatures is studied, as shown in Figure 3, where $\varepsilon_{g}=\alpha_{g w}=\alpha_{g s}=0.3$. As can be seen from the figure, the higher the temperature, the higher the heat exchange capacity on the surface of the

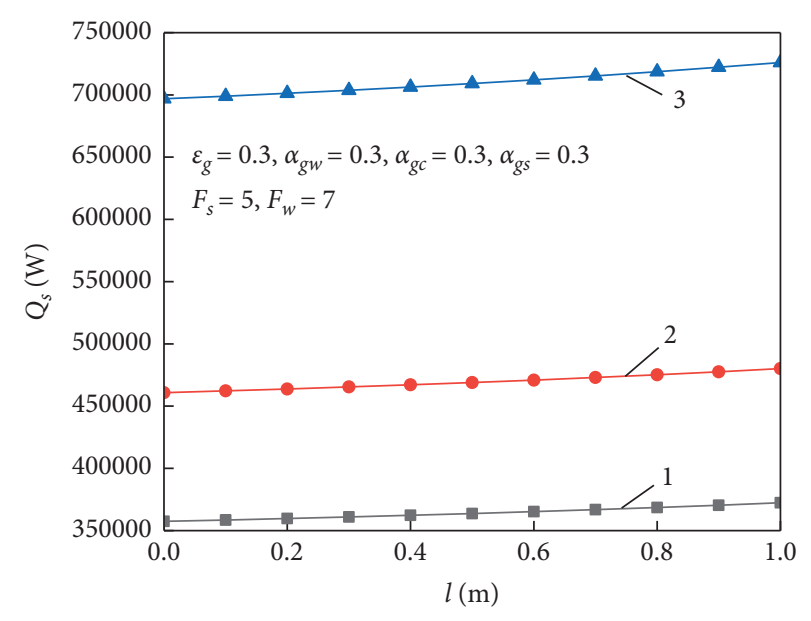

FIgURE 3: Variation curve of heat exchange capacity of billet with length of heat carrier at different temperatures. $1 . T_{\mathrm{g}}=1300 \mathrm{~K}$, $T_{\mathrm{s}}=500 \mathrm{~K} ; 2 . T_{\mathrm{g}}=1500 \mathrm{~K}, T_{\mathrm{s}}=1100 \mathrm{~K} ; 3 . T_{\mathrm{g}}=1800 \mathrm{~K}, T_{\mathrm{s}}=1500 \mathrm{~K}$.

billet. With the increase of the length of the intermediate heat carrier, the heat exchange capacity on the surface of the billet also increases gradually, indicating that more heat in the furnace is transferred by intermediate heat carrier to the surface of the billet and heat transfer in the furnace is enhanced. Although the longer the intermediate heat carrier is, the better the enhancement effect of heat transfer will be, considering the actual size of the furnace, $0.5 \mathrm{~m}$ is taken as the length of the heat carrier below for discussion. In the case of $l=0.5$, the heat exchange capacity of billet increases by $1.44 \%$.

The furnace width direction is taken as abscissa $(V)$ and the furnace height direction is taken as ordinate $(Y)$, as shown in Figure 4. Considering that the furnace width is $5 \mathrm{~m}$, 19 points on average are taken from the furnace top. The heat exchange capacity $Q_{s}$ on the surface of billet when heat carrier is at different points and the heat flux $Q_{s_{-} w}$ from furnace wall to billet are calculated.

It can be seen from Figures 5(a), 5(c), and 5(e) that, at three different temperatures, the heat exchange capacity $Q_{s}$ on the surface of the billet is the largest when the intermediate heat carrier is in the middle of the furnace top and decreases gradually when the intermediate heat carrier is closer to the wall surface. Moreover, at different temperatures, the heat transferred by the heat carrier at the center is about $1 \%$ more than that transferred by the heat carrier close to the furnace wall. It can be seen from Figures 5(b), 5(d), and 5(f) that, when the intermediate heat carrier is in the middle of the furnace top, the heat flux $Q_{s_{-} w}$ from the furnace wall to the billet is maximized. While the closer the intermediate heat carrier is to the furnace wall, the less heat flux $Q_{s_{-} w}$ from the furnace wall to the billet. Because the closer the intermediate heat carrier is to the furnace wall, the more the heat flux from the furnace wall to the billet is blocked; thus, the heat flux $Q_{s}$ on the billet surface is reduced. When choosing the position of intermediate heat carrier on the top of furnace, it is necessary to locate it as close as possible to the center of the furnace top to achieve higher heat transfer efficiency. 


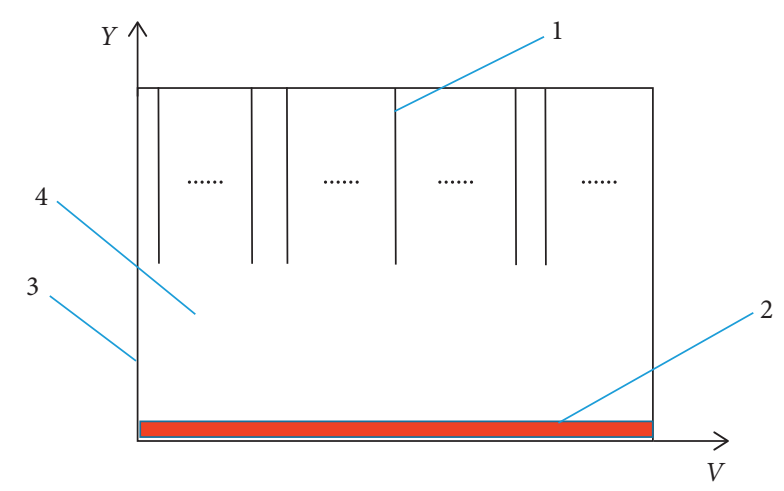

FIGURE 4: Schematic diagram of heat carrier at different positions on furnace top. 1. Intermediate heat carrier. 2. Billet. 3. Furnace wall. 4. Furnace gas.

When the emissivity of furnace gas and absorptivity of furnace wall were given at three different temperatures, the impact of emissivity variation of heat carrier at the center of furnace top on the heat exchange capacity $Q_{s}$ of billet was studied.

It can be seen from Figure 6 that, in case of $\varepsilon_{g}>\alpha_{g w}$, with the gradual increase of emissivity $\varepsilon_{c}$ of the intermediate heat carrier, the heat flux on the surface of the billet also increases with an increment of $0.2 \%, 0.3 \%$, and $0.4 \%$, respectively, at three temperatures.

It can be seen from Figure 7 that, in case of $\varepsilon_{g}<\alpha_{g w}$, with the gradual increase of emissivity $\varepsilon_{c}$ of the intermediate heat carrier, the heat flux on the surface of the billet decreases by $0.5 \%, 0.6 \%$, and $0.8 \%$, respectively, at three temperatures.

It can be seen from Figure 8 that, in case of $\varepsilon_{g}=\alpha_{g w}$, with the gradual increase of emissivity $\varepsilon_{c}$ of the intermediate heat carrier, the heat flux on the surface of the billet decreases with decrease around $0.2 \%$ at three temperatures.

From the above three figures, it can be concluded that, in case of $\varepsilon_{g}>\alpha_{g w}$, with the gradual increase of emissivity of the heat carrier, the heat exchange capacity $Q_{s}$ on the billet surface also increases gradually, indicating that the increase of emissivity of heat carrier enhances the heat flux to the surface of billet to some extent. However, in case of $\varepsilon_{g} \leq \alpha_{g w}$, increasing $\varepsilon_{c}$ leads to the decrease of $Q_{s}$. Therefore, the emissivity of heat carrier should be selected according to the relationship between $\varepsilon_{g}$ and $\alpha_{g w}$, so as to enhance the thermal efficiency in the furnace. The difference in the emissivity value of the intermediate heat carrier can be obtained by the different materials [45].

In this article, an intermediate heat carrier with length of $0.5 \mathrm{~m}$ was added at the center of the furnace top. The value of $Q_{s}$ and $Q_{s_{-} w}$ in case of $\varepsilon_{g}>\alpha_{g w}, \varepsilon_{g}=\alpha_{g w}$ and $\varepsilon_{g}<\alpha_{g w}$ were calculated, respectively, and compared with the data in the literature to illustrate the impact of intermediate heat carrier on the effect of enhancing heat transfer in the furnace under different gas emissivities and wall absorptivities.

As can be seen from Figure $9(\mathrm{a}), Q_{s}$ increases gradually with the emissivity increase of the furnace wall. With the addition of intermediate heat carrier, the heat exchange capacity of the billet increases at different wall emissivities; and the higher the temperature, the greater the increase of $Q_{s}$. Furthermore, from Figure 9(b), it can be seen that, in case of $T_{g}=1300 \mathrm{~K}, T_{s}=500 \mathrm{~K}$, the maximum value of $Q_{s}$ difference is taken when $\varepsilon_{w}$ is 1 , which is about $16030 \mathrm{~W}$. In the case of $T_{g}=1500 \mathrm{~K}, T_{s}=1100 \mathrm{~K}$, the maximum difference of $Q_{s}$ is taken when $\varepsilon_{w}$ is within $0.7 \sim 0.9$, which is about $27162 \mathrm{~W}$. In case of $T_{g}=1800 \mathrm{~K}, T_{s}=1500 \mathrm{~K}$, the maximum value of $Q_{s}$ difference is taken when $\varepsilon_{w}=0.7$, which is about $55041 \mathrm{~W}$. Thus, it can be seen that, in case of $\varepsilon_{g}>\alpha_{g w}$, with the increase of temperature in furnace, the emissivity $\varepsilon_{w}$ of the furnace wall corresponding to the peak heat exchange capacity of the furnace model with intermediate heat carrier decreases gradually.

The heat transfer from the wall to the billet is shown in Figure 9(c). It can be seen that the heat flux from the furnace wall to the billet increases due to the existence of intermediate heat carrier. At different temperatures, $\varepsilon_{w}$ corresponding to the peak value of increment has no obvious variation, which is taken at about 0.9 . The peak value of $Q_{s_{-} w}$ difference corresponding to the temperature from low to high increases by $285 \%, 277 \%$, and $270 \%$, respectively, compared with the lowest value.

As can be seen from Figures 10(a) and 10(b), $Q_{s}$ decreases gradually with the emissivity increase of the furnace wall. With the addition of intermediate heat carrier, the heat exchange capacity $Q_{s}$ of billet increases, but the higher the temperature, the lower the increase of $Q_{s}$. In the case of $T_{g}=1300 \mathrm{~K}, T_{s}=500 \mathrm{~K}$, the difference of heat exchange capacity of billet, with or without intermediate heat carrier, gradually decreases with the increase of $\varepsilon_{w}$, and the maximum value is obtained when $\varepsilon_{w}=0.1$, which is about $4201 \mathrm{~W}$. In the case of $T_{g}=1500 \mathrm{~K}, T_{s}=1100 \mathrm{~K}, Q_{s}$ difference decreases at the beginning and increases slowly after $\varepsilon_{w}=0.3$; the maximum value is obtained when $\varepsilon_{w}=1$, which is about $3659 \mathrm{~W}$. In the case of $T_{g}=1800 \mathrm{~K}, T_{s}=1500 \mathrm{~K}, Q_{s}$ difference first decreases and then increases, and the maximum value for the difference is obtained when $\varepsilon_{w}=1$, which is $3214 \mathrm{~W}$.

It can be seen from Figure 10(c) that the difference of heat exchange capacity from the furnace wall, with or without intermediate heat carrier, to the billet first increases and then decreases at different temperatures, and the peak value of $Q_{s_{-} w}$ difference is obtained when $\varepsilon_{w}=0.7$. The peak value of $Q_{s_{-} w}$ difference corresponding to the temperature from low to high increases by $219 \%, 218 \%$, and $214 \%$, respectively, compared with the lowest value.

It can be seen from Figures 11(a) and 11(b) that, in case of $\varepsilon_{g}=\alpha_{g w}$, with the emissivity increase of the furnace wall, the value of $Q_{s}$ remains basically unchanged. With the addition of intermediate heat carrier, the heat exchange capacity $Q_{s}$ of billet increases, and the higher the temperature is, the more the increase of $Q_{s}$ is; the difference of $Q_{s}$ increases first and then decreases with the increase of $\varepsilon_{w}$, and no matter how $T_{g}$ and $T_{s}$ change, the peak value of $Q_{s}$ difference is always taken where $\varepsilon_{w}=0.8$, indicating that the maximum value of $Q_{s}$ increment, after intermediate heat carrier is added, is not affected by $\varepsilon_{w}$ and the maximum value of $Q_{s}$ difference from low to high temperature is $6277 \mathrm{~W}$, $8105 \mathrm{~W}$, and $12276 \mathrm{~W}$, respectively. 


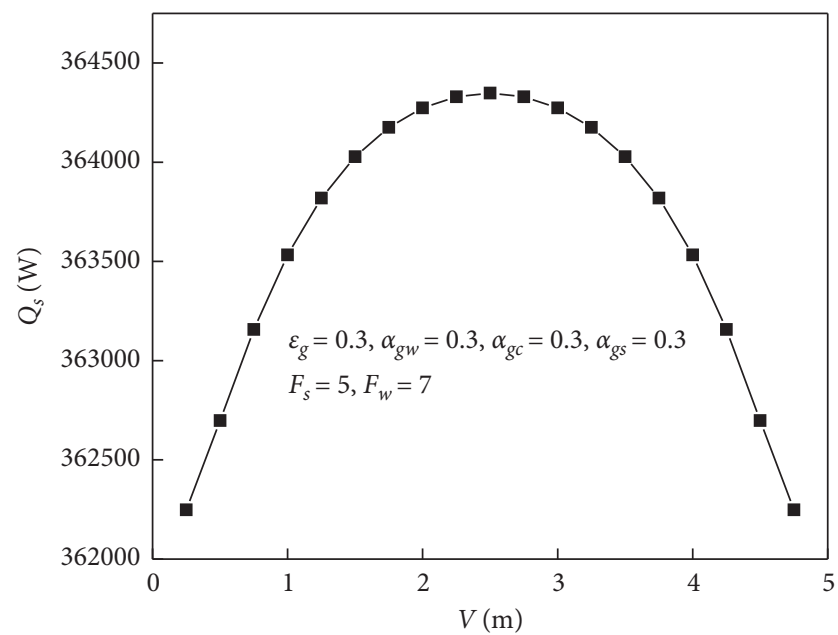

(a)

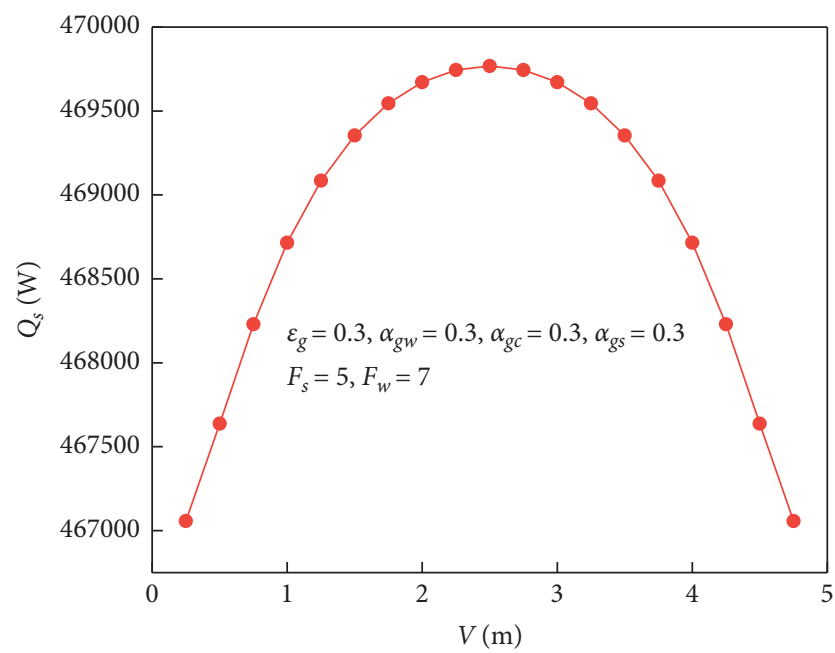

(c)

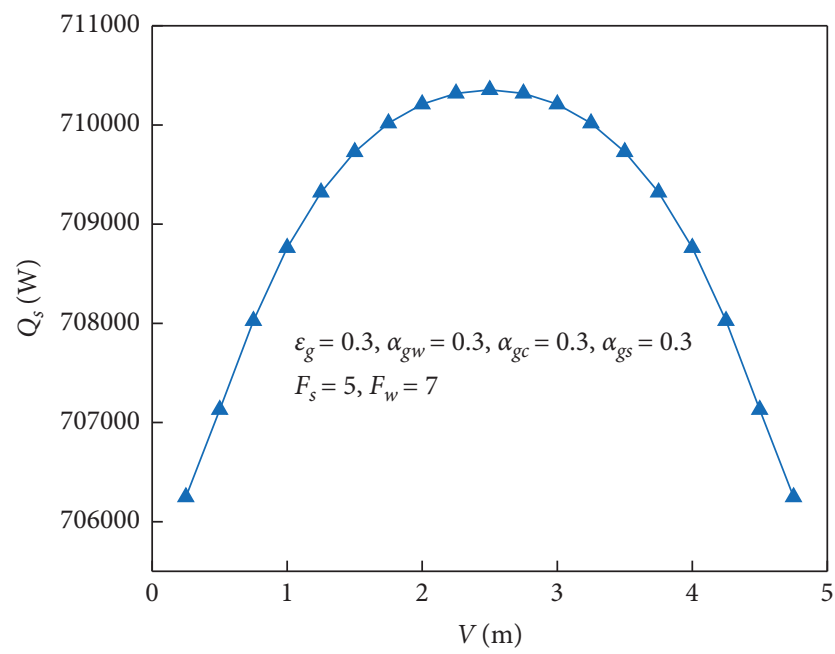

(e)

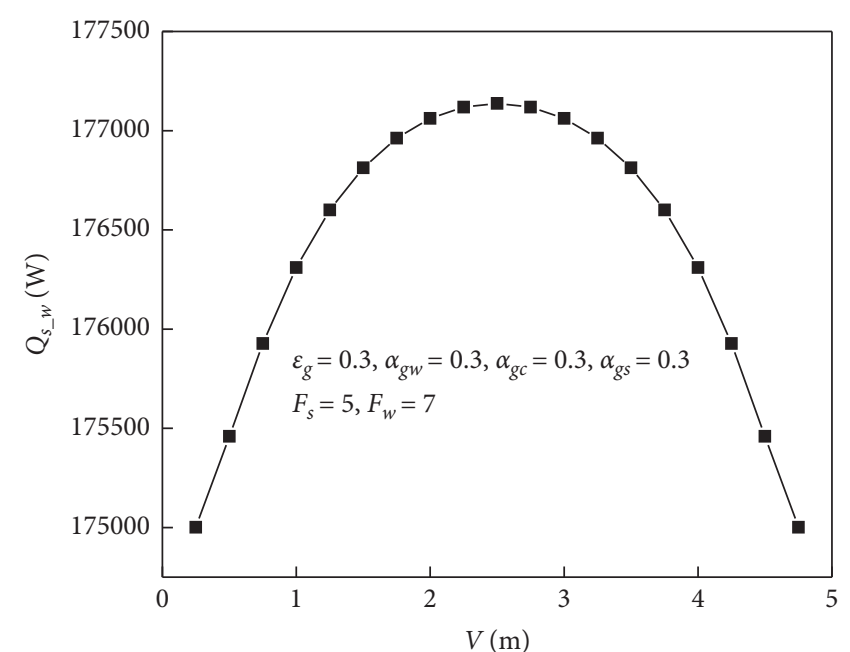

(b)

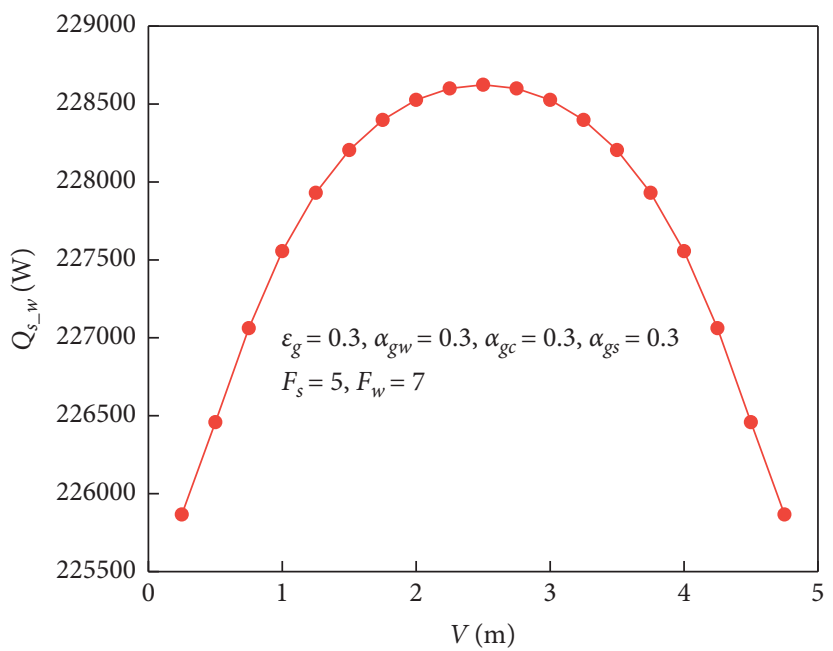

(d)

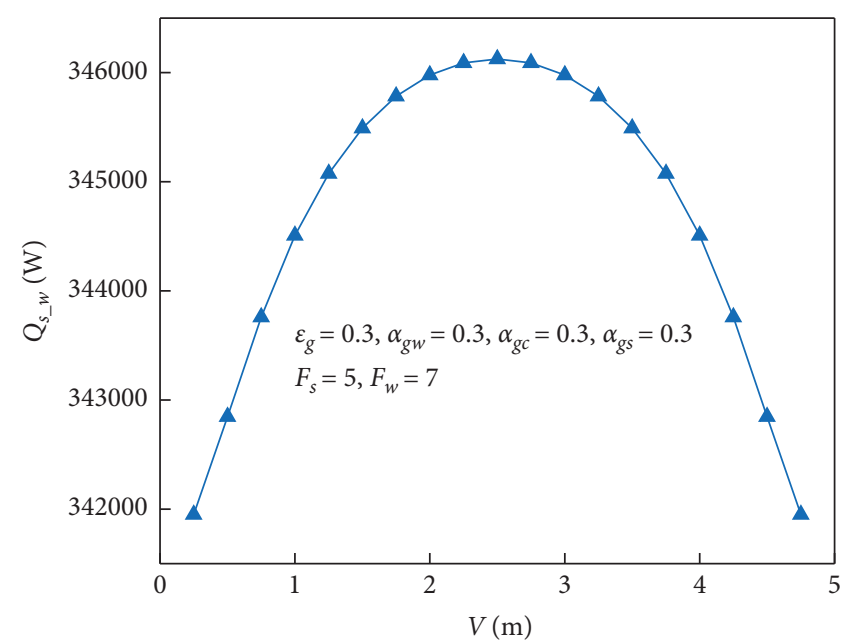

(f)

FIGURE 5: Variation curve of $Q_{s}$ and $Q_{s_{-} w}$ when the intermediate heat carrier at different positions on furnace top. (a, b) $T_{g}=1300 \mathrm{~K}$, $T_{s}=500 \mathrm{~K} ;(\mathrm{c}, \mathrm{d}) T_{g}=1500 \mathrm{~K}, T_{s}=1100 \mathrm{~K} ;(\mathrm{e}, \mathrm{f}) T_{g}=1800 \mathrm{~K}, T_{s}=1500 \mathrm{~K}$. 


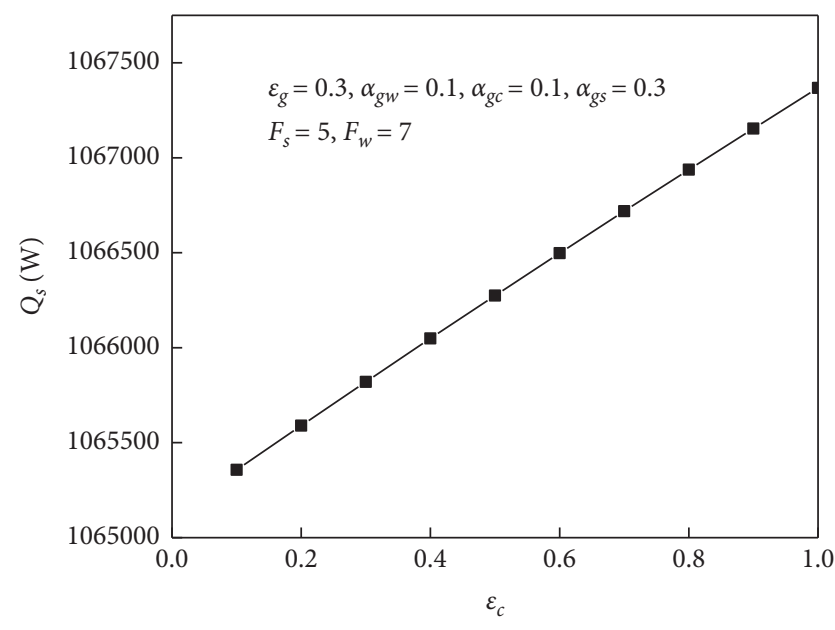

(a)

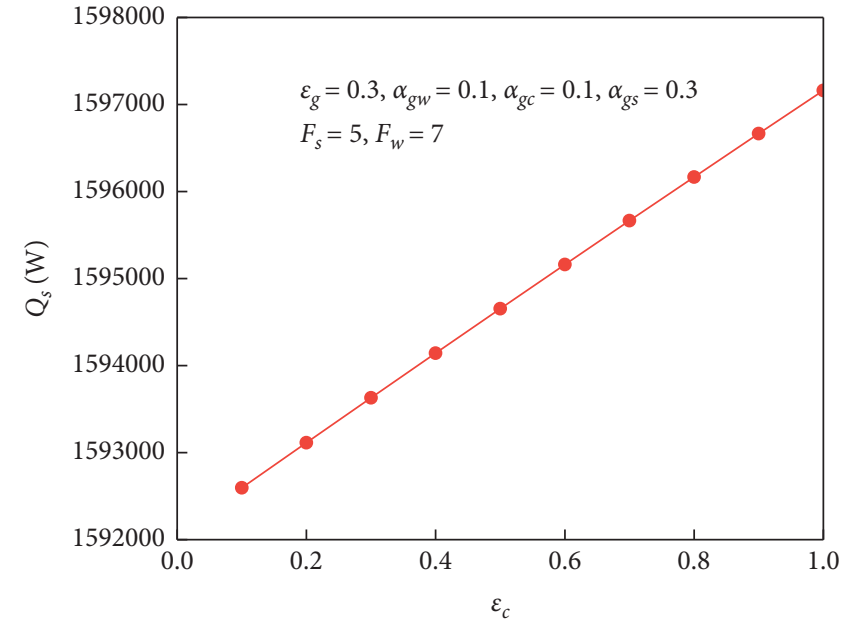

(b)

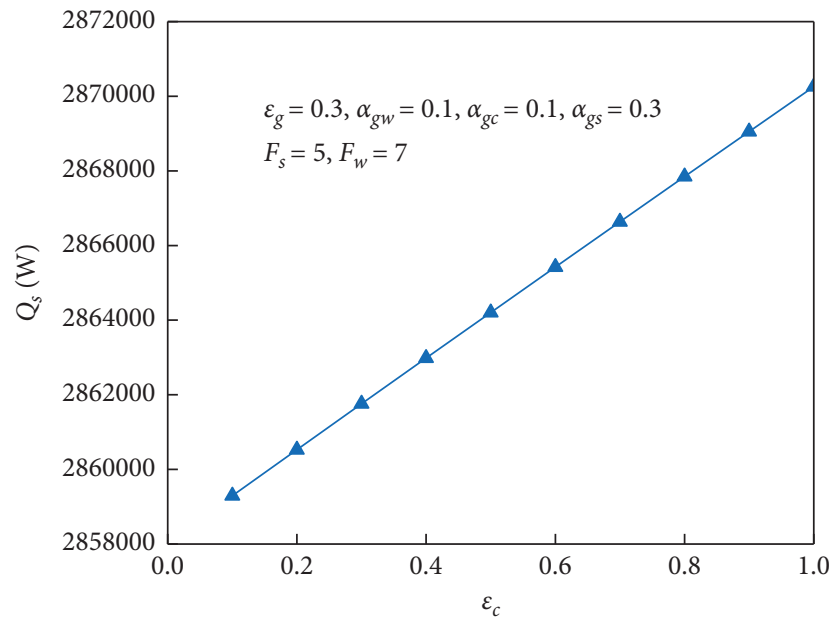

(c)

FIGURE 6: In case of $\varepsilon_{g}>\alpha_{g w}$, at different temperatures, the impact of emissivity variation of intermediate heat carrier on the heat exchange capacity of the billet. (a) $T_{g}=1300 \mathrm{~K}, T_{s}=500 \mathrm{~K}$; (b) $T_{g}=1500 \mathrm{~K}, T_{\mathrm{s}}=1100 \mathrm{~K}$; (c) $T_{g}=1800 \mathrm{~K}, T_{s}=1500 \mathrm{~K}$.

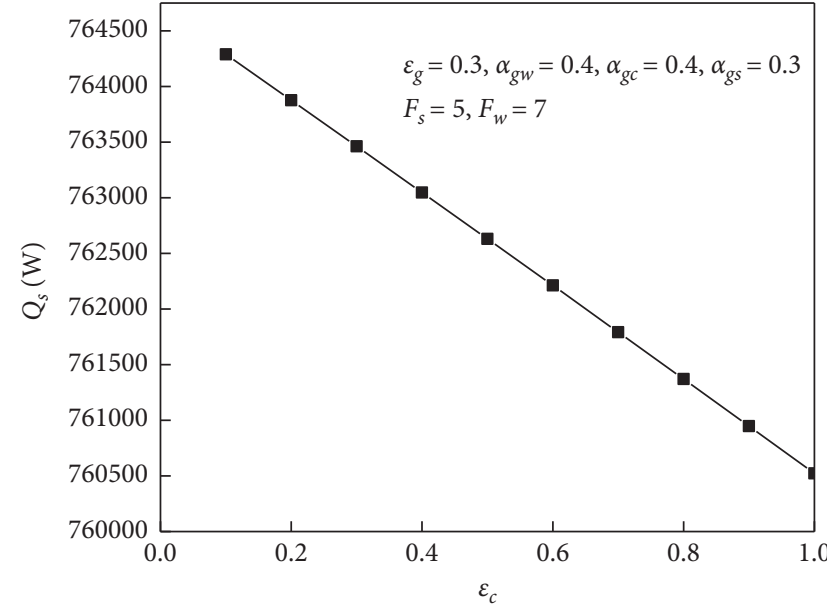

(a)

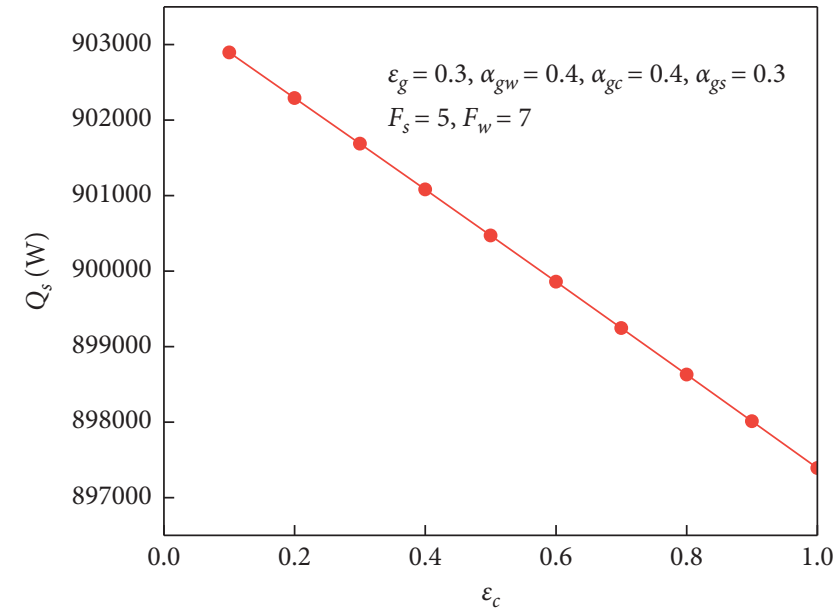

(b)

Figure 7: Continued. 


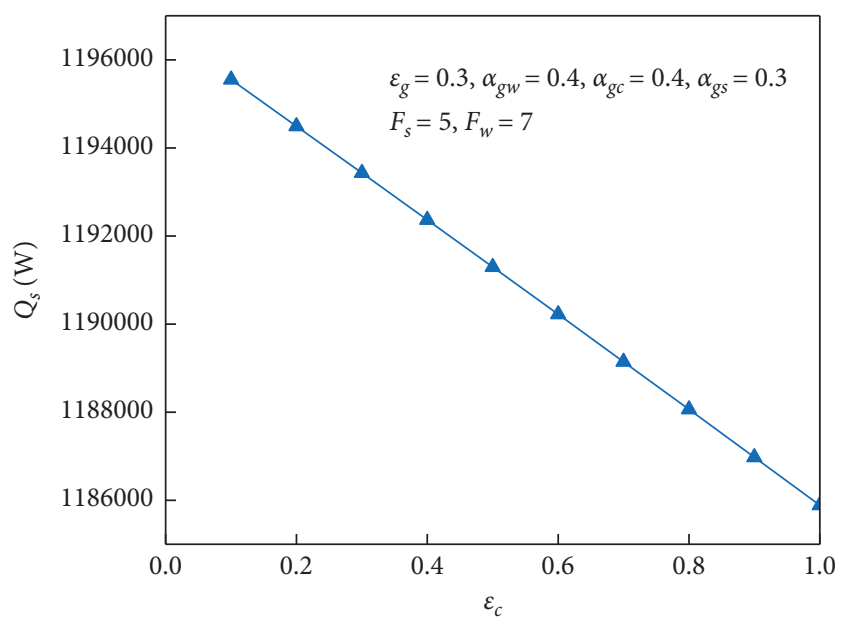

(c)

Figure 7: In case of $\varepsilon_{g}<\alpha_{g w}$, at different temperatures, the impact of emissivity variation of intermediate heat carrier on the heat exchange capacity of the billet. (a) $T_{g}=1300 \mathrm{~K}, T_{s}=500 \mathrm{~K}$; (b) $T_{g}=1500 \mathrm{~K}, T_{s}=1100 \mathrm{~K}$; (c) $T_{g}=1800 \mathrm{~K}, T_{s}=1500 \mathrm{~K}$.

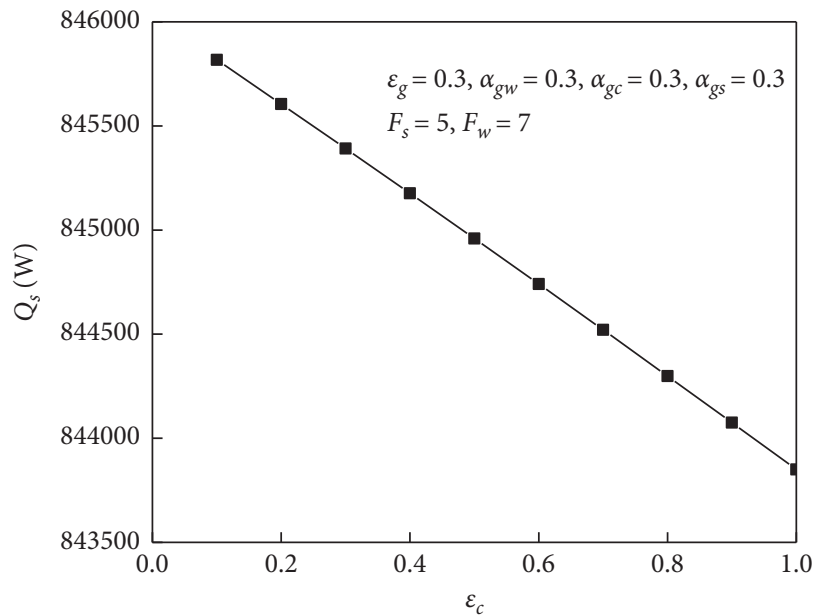

(a)

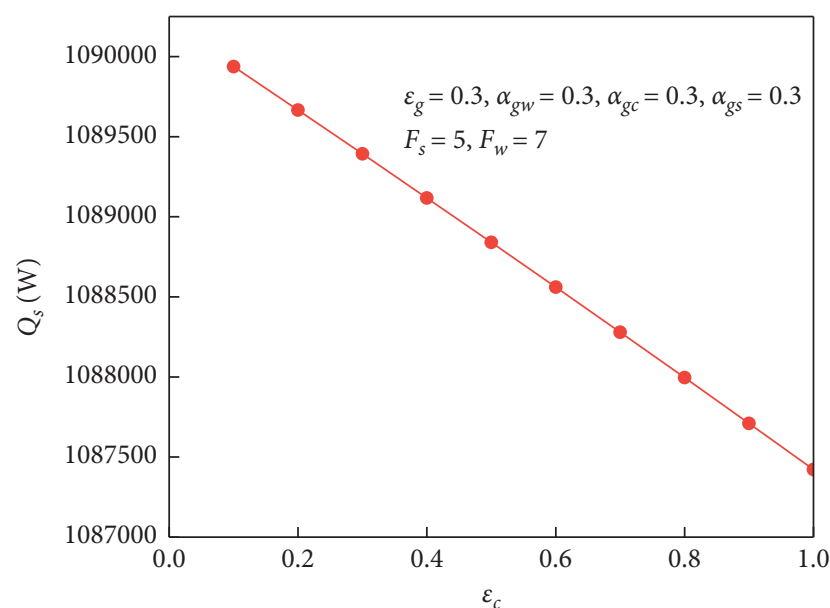

(b)

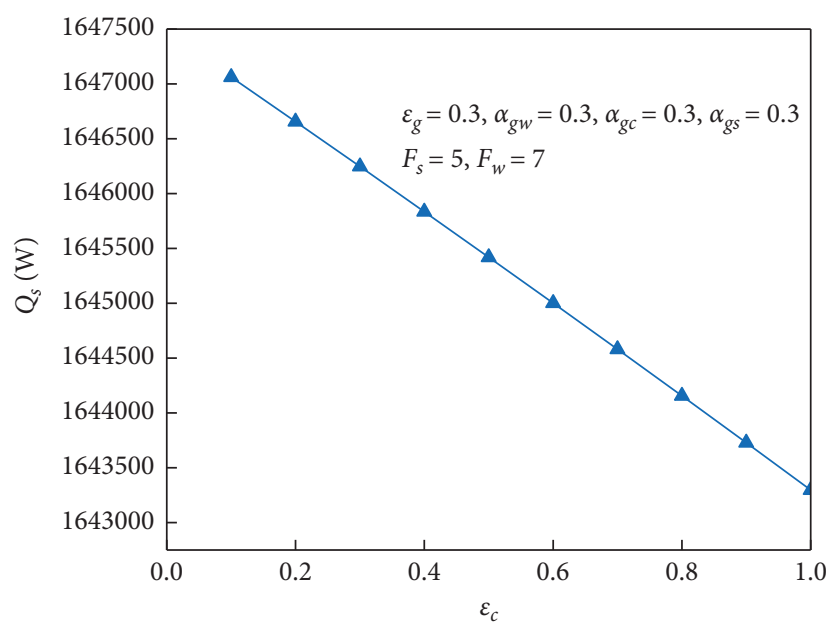

(c)

FIGURE 8: In case of $\varepsilon_{g}=\alpha_{q w}$, at different temperatures, the impact of emissivity variation of intermediate heat carrier on the heat exchange capacity of the billet. (a) $T_{g}=1300 \mathrm{~K}, T_{s}=500 \mathrm{~K}$; (b) $T_{g}=1500 \mathrm{~K}, T_{s}=1100 \mathrm{~K}$; (c) $T_{g}=1800 \mathrm{~K}, T_{s}=1500 \mathrm{~K}$. 


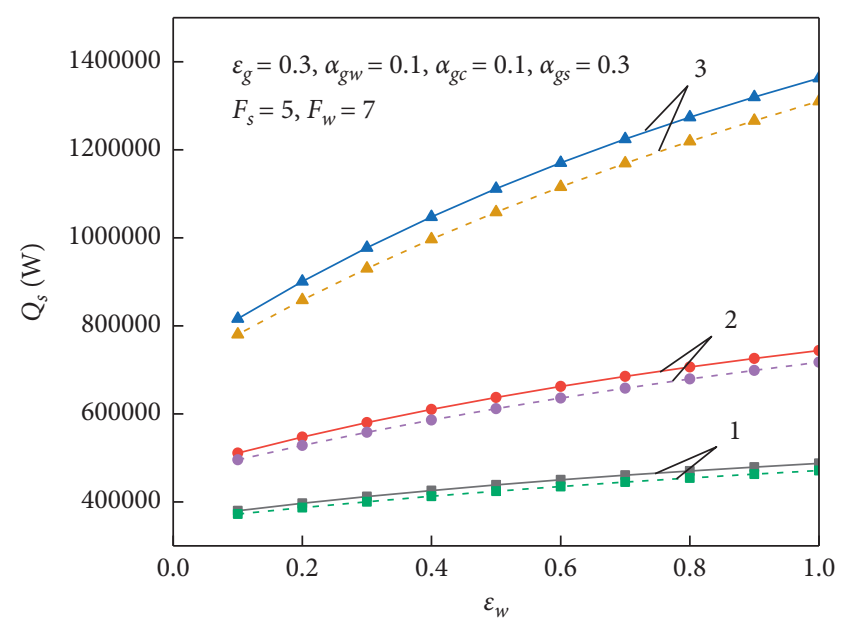

(a)

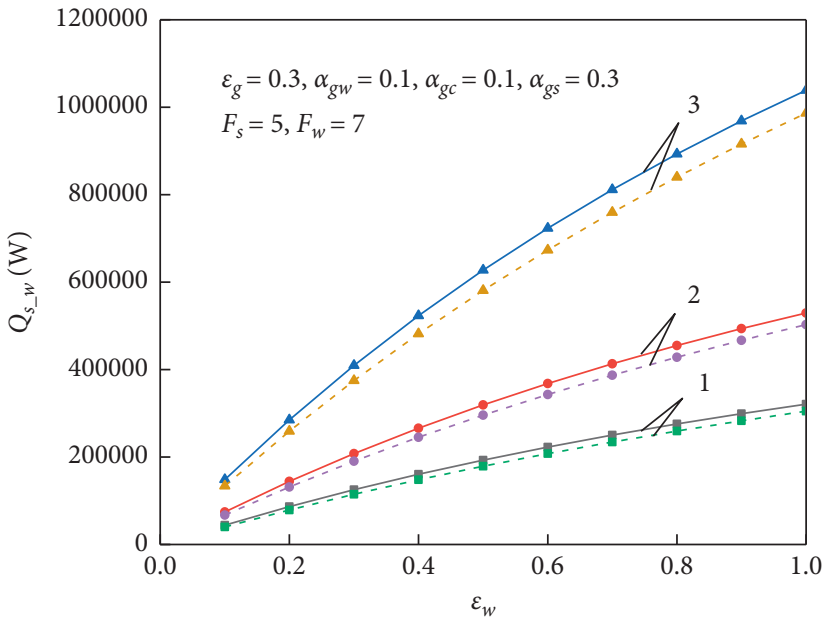

(c)

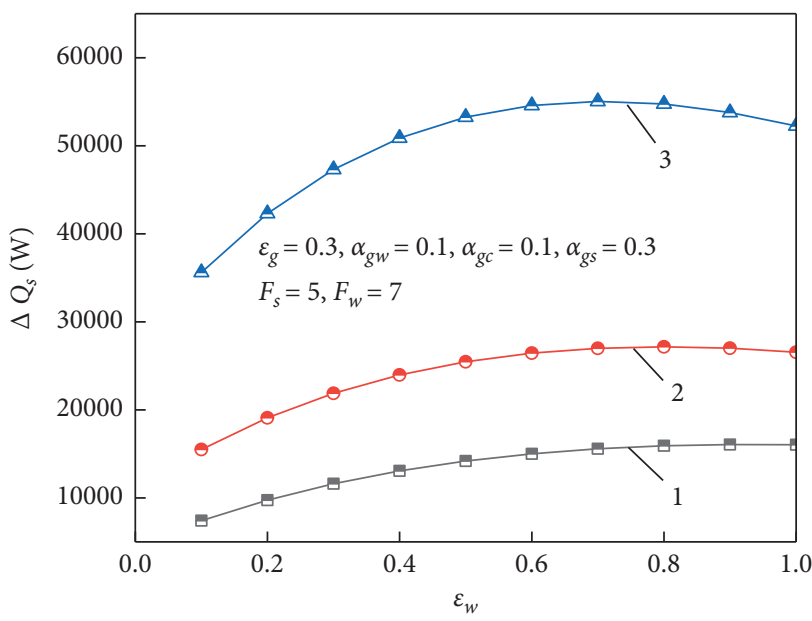

(b)

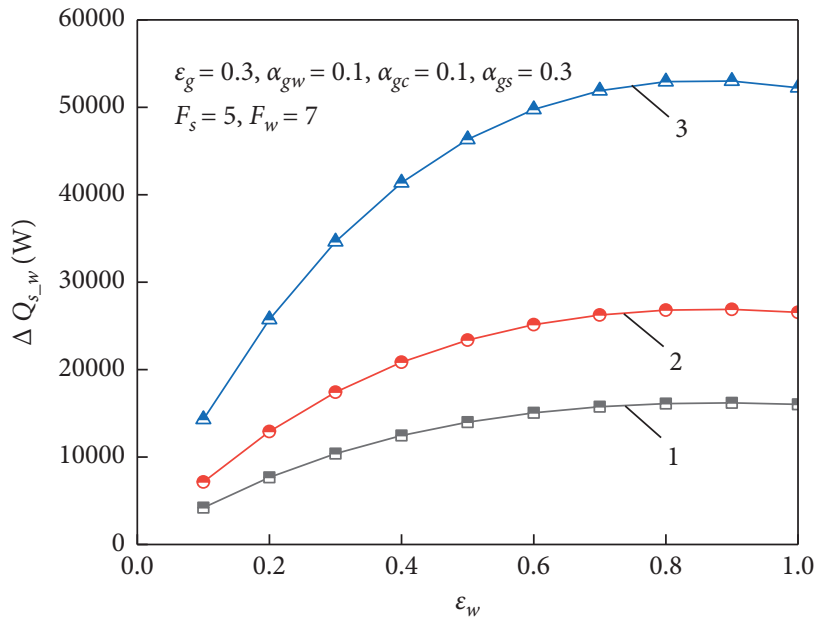

(d)

Figure 9: Comparison between the model in this article and that in literature when $\varepsilon_{g}>\alpha_{g w} 1 . T_{g}=1300 \mathrm{~K}, T_{s}=500 \mathrm{~K} ; 2 . T_{g}=1500 \mathrm{~K}$, $T_{\mathrm{s}}=1100 \mathrm{~K} ; 3 . T_{g}=1800 \mathrm{~K}, T_{s}=1500 \mathrm{~K}$ intermediate heat carrier No intermediate heat carrier.

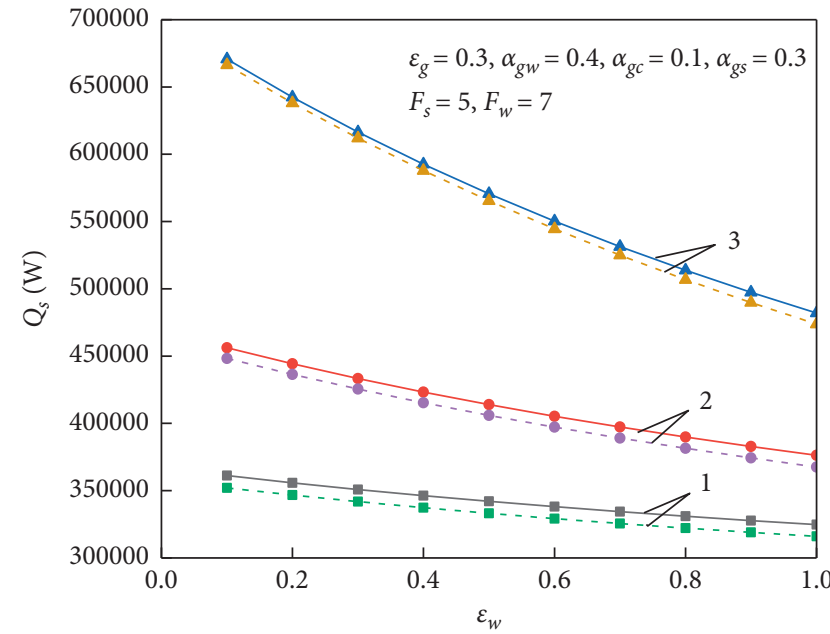

(a)

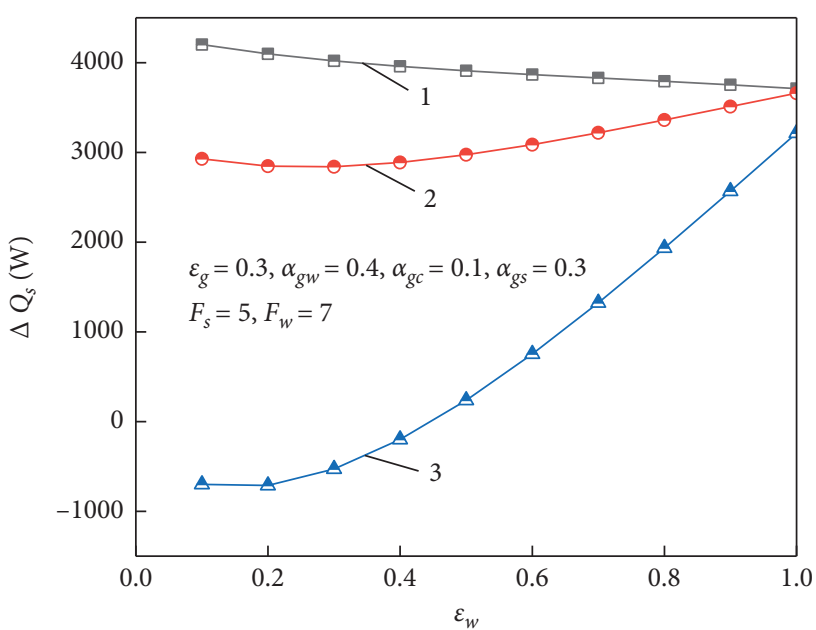

(b)

FIgURE 10: Continued. 


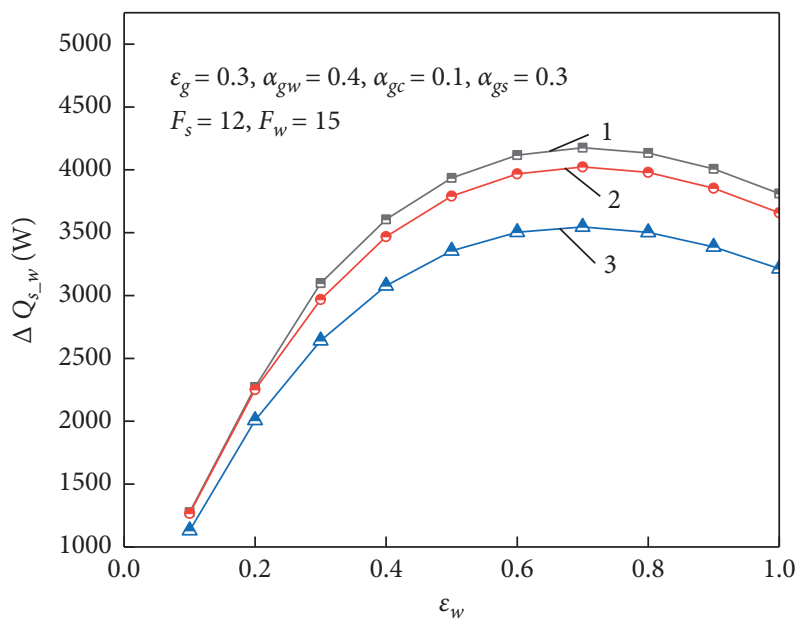

(c)

Figure 10: Comparisons between the model in this article and that in literature for $\varepsilon_{g}<\alpha_{g w} .1 . T_{g}=1300 \mathrm{~K}, T_{s}=500 \mathrm{~K} ; 2 . T_{g}=1500 \mathrm{~K}$, $T_{s}=1100 \mathrm{~K} ; 3 . T_{g}=1800 \mathrm{~K}, T_{s}=1500 \mathrm{~K}$ Intermediate heat carrier No intermediate heat carrier.

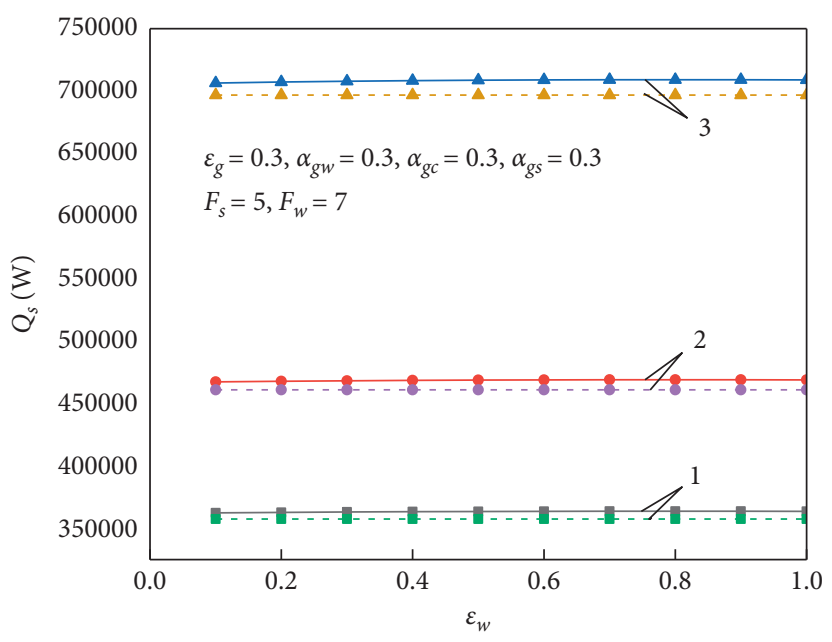

(a)

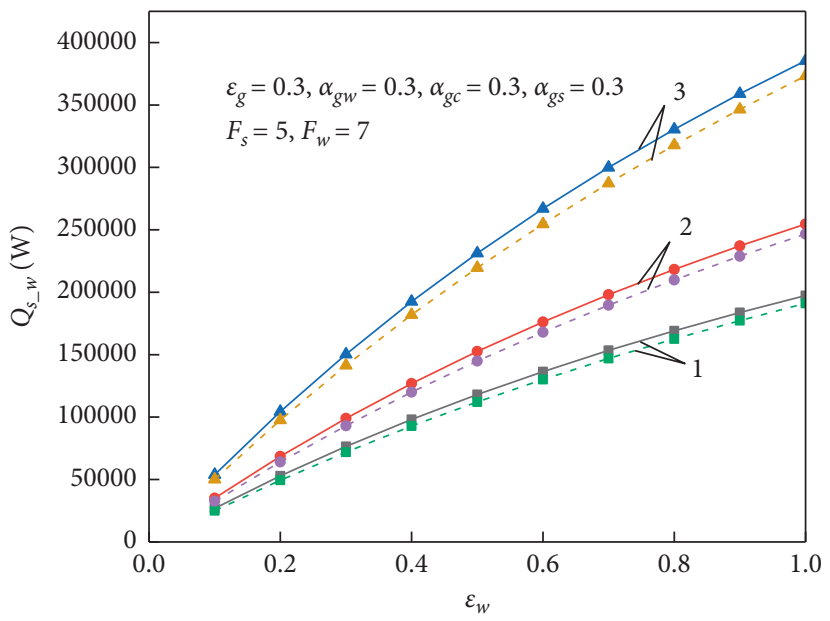

(c)

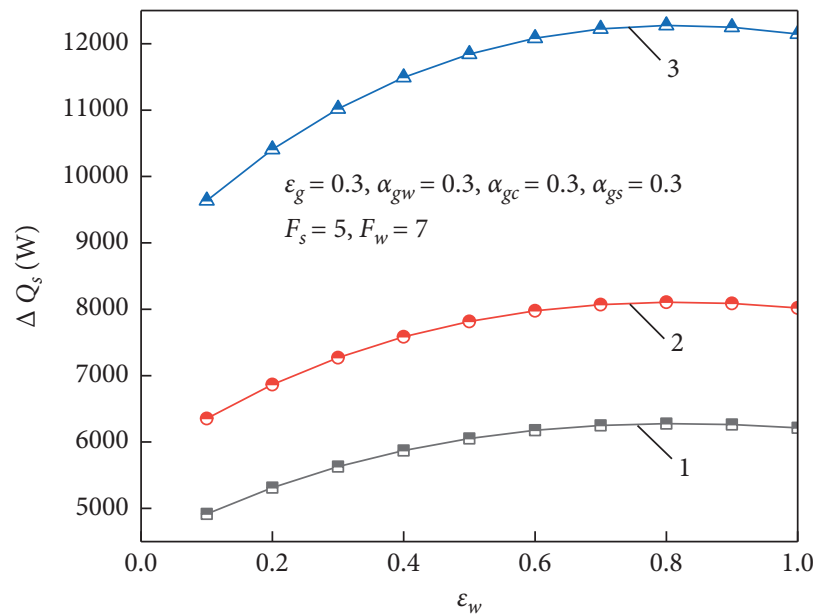

(b)

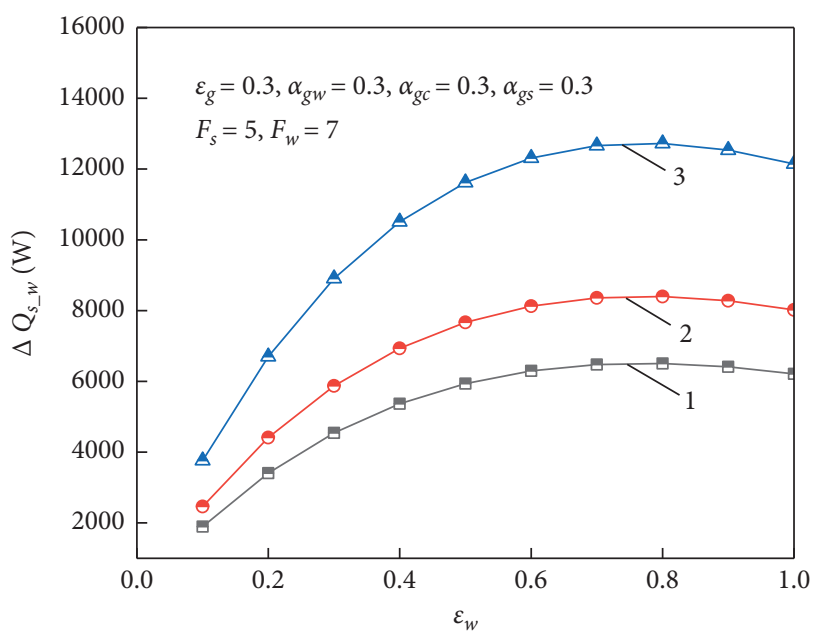

(d)

FiguRE 11: In case of $\varepsilon_{g}=\alpha_{g w}$, data comparisons between the model in this article and that in literature. $1 . T_{g}=1300 \mathrm{~K}, T_{s}=500 \mathrm{~K} ; 2$. $T_{g}=1500 \mathrm{~K}, T_{s}=1100 \mathrm{~K} ; 3 . T_{g}=1800 \mathrm{~K}, T_{s}=1500 \mathrm{~K}$ Intermediate heat carrier No intermediate heat carrier. 
It can be seen from Figure 11(c), in case of $\varepsilon_{g}=\alpha_{g w}$, with the emissivity increase of the furnace wall, the value of $Q_{s_{-} w}$ increases. With the addition of intermediate heat carrier, the heat flux from the furnace wall to the billet increases. It can be seen from Figure 11(d) that, at different temperatures, with and without intermediate heat carrier, $Q_{s_{-} w}$ difference increases first and then decreases, and the peak value of $Q_{s_{-} w}$ difference is always taken when $\varepsilon_{w}=0.8$. The peak value of $Q_{s_{-} w}$ difference corresponding to the temperature from low to high increases by $243 \%, 241 \%$, and $238 \%$, respectively, compared with the lowest value.

\section{Conclusion}

In this study, a one-zone quaternary system model in the furnace with an intermediate heat carrier is established to derive the impact of length, position, and emissivity of the heat carrier on heat exchange capacity of the billet surface, and a conclusion by comparing with the literature data is summarized.

From the analysis, it can be seen that the longer the intermediate heat carrier located at the top of the furnace, the larger the heat exchange capacity on the billet surface. Thus, the length of the heat carrier can be increased as much as possible in the maximum allowable space of the furnace to obtain higher heat flux. The position of the intermediate heat carrier also affects the heat flux on the billet surface. When the heat carrier is located in the center of the furnace top, the billet gets higher heat flux, and the closer it is to the two sides, the lower the heat flux is. In the actual layout of the heat carrier on the furnace top, the heat carrier should be arranged in the center of the furnace top when possible. At the same time, in the case of $\varepsilon_{g}>\alpha_{g w}$, the heat exchange capacity of the billet surface increases by increasing the surface emissivity of the intermediate heat carrier, while in the case of $\varepsilon_{g} \leq \alpha_{g w}$, the heat exchange capacity of the billet surface decreases by increasing the surface emissivity of the intermediate heat carrier. Therefore, when choosing the emissivity of the intermediate heat carrier, the actual situation of $\varepsilon_{g}$ and $\alpha_{g w}$ should be considered. By comparing with the literature data, it is concluded that the heat exchange capacity of the billet increases to some extent with the addition of intermediate heat carrier regardless of $\varepsilon_{g}$ and $\alpha_{g w}$ values, and the amount of increase is related to the temperature of the furnace gas and the billet.

In summary, the addition of the intermediate heat carrier has a positive impact on the heat exchange capacity of the billet surface. However, in practical application, the impact of length, position, and emissivity of the heat carrier should be taken into account for better heat transfer enhancement effect in a furnace.

\section{Nomenclature}

$\begin{array}{ll}s: & \text { Slab } \\ w: & \text { Furnace wall } \\ g: & \text { Flue gas }\end{array}$

c: $\quad$ Intermediate heat carrier

F: $\quad$ Area $\left(\mathrm{m}^{2}\right)$

$l$ : $\quad$ Length of the intermediate radiator $(\mathrm{m})$

$d$ : Furnace weight (m)

$h$ : $\quad$ Furnace height $(\mathrm{m})$

T: $\quad$ Temperature (K)

$Q_{e}: \quad$ Heat loss to the environment through $w(\mathrm{~W})$

$Q_{s}$ : Heat flow of $s(\mathrm{~W})$

$Q_{s_{-} w}$ : Heat flow of $s$ surface, which is from $w(\mathrm{~W})$

\section{Direct Radiative Exchange Areas}

${ }_{g} g_{s}:$ Direct exchange area when energy radiates from $g$ and arrives at $s$; meanwhile, $g$ is the only radiation source $\left(\mathrm{m}^{2}\right)$

${ }_{g} g_{w}:$ Direct exchange area when energy radiates from $g$ and arrives at $w$; meanwhile, $g$ is the only radiation source $\left(\mathrm{m}^{2}\right)$

${ }_{g} g_{c}:$ Direct exchange area when energy radiates from $g$ and arrives at $c$; meanwhile, $g$ is the only radiation source $\left(\mathrm{m}^{2}\right)$

${ }_{g} w_{s}:$ Direct exchange area when energy radiates from the wall and arrives at the slab; meanwhile, the gas is the only radiation source in the system $\left(\mathrm{m}^{2}\right)$

${ }_{g} w_{c}$ : Direct exchange area when energy radiates from $w$ and arrives at $c$; meanwhile, $g$ is the only radiation source $\left(\mathrm{m}^{2}\right)$

$g_{c}$ : Direct exchange area when energy radiates from $s$ and arrives at $c$; meanwhile, $g$ is the only radiation source $\left(\mathrm{m}^{2}\right)$

$g w_{w}$ : Direct exchange area when energy radiates from $w$ and arrives at $w$; meanwhile, $g$ is the only radiation source $\left(\mathrm{m}^{2}\right)$

${ }_{s} g_{s}: \quad$ Direct exchange area when energy radiates from $g$ and arrives at $s$; meanwhile, $s$ is the only radiation source $\left(\mathrm{m}^{2}\right)$

${ }_{s} g_{w}:$ Direct exchange area when energy radiates from $g$ and arrives at $w$; meanwhile, $s$ is the only radiation source $\left(\mathrm{m}^{2}\right)$

${ }_{s} g_{c}:$ Direct exchange area when energy radiates from $g$ and arrives at $c$; meanwhile, $s$ is the only radiation source $\left(\mathrm{m}^{2}\right)$

${ }_{s} w_{s}$ : Direct exchange area when energy radiates from $w$ and arrives at $s$; meanwhile, $s$ is the only radiation source $\left(\mathrm{m}^{2}\right)$

${ }_{s} w_{c}$ : Direct exchange area when energy radiates from $w$ and arrives at $c$; meanwhile, $s$ is the only radiation source $\left(\mathrm{m}^{2}\right)$

$s_{s}$ : Direct exchange area when energy radiates from $s$ and arrives at $c$; meanwhile, $s$ is the only radiation source $\left(\mathrm{m}^{2}\right)$

${ }_{s} w_{w}$ : Direct exchange area when energy radiates from $w$ and arrive at $w$; meanwhile, $s$ is the only radiation source $\left(\mathrm{m}^{2}\right)$

${ }_{w} g_{s}:$ Direct exchange area when energy radiates from $g$ and arrives at $s$; meanwhile, $w$ is the only radiation source $\left(\mathrm{m}^{2}\right)$ 
${ }_{w} \mathcal{G}_{w}$ : Direct exchange area when energy radiates from $g$ and arrives at $w$; meanwhile, $w$ is the only radiation source $\left(\mathrm{m}^{2}\right)$

${ }_{w} g_{c}$ : Direct exchange area when energy radiates from $g$ and arrives at $c$; meanwhile, $w$ is the only radiation source $\left(\mathrm{m}^{2}\right)$

${ }_{w} w_{s}$ : Direct exchange area when energy radiates from $w$ and arrives at $s$; meanwhile, $w$ is the only radiation source $\left(\mathrm{m}^{2}\right)$

${ }_{w} w_{c}$ : Direct exchange area when energy radiates from $w$ and arrives at $c$; meanwhile, $w$ is the only radiation source $\left(\mathrm{m}^{2}\right)$

${ }_{w} s_{c}$ : Direct exchange area when energy radiates from $s$ and arrives at $c$; meanwhile, $w$ is the only radiation source $\left(\mathrm{m}^{2}\right)$

${ }_{w} w_{w}$ : Direct exchange area when energy radiates from $w$ and arrives at $w$, meanwhile, $w$ is the only radiation source $\left(\mathrm{m}^{2}\right)$

${ }_{c} g_{s}:$ Direct exchange area when energy radiates from $g$ and arrives at $s$; meanwhile, $c$ is the only radiation source $\left(\mathrm{m}^{2}\right)$

${ }_{c} g_{w}$ : Direct exchange area when energy radiates from $g$ and arrives at $w$; meanwhile, $c$ is the only radiation source $\left(\mathrm{m}^{2}\right)$

${ }_{c} g_{c}$ : Direct exchange area when energy radiates from $g$ and arrives at $c$; meanwhile, $c$ is the only radiation source $\left(\mathrm{m}^{2}\right)$

${ }_{c} w_{s}$ : Direct exchange area when energy radiates from $w$ and arrives at $s$; meanwhile, $c$ is the only radiation source $\left(\mathrm{m}^{2}\right)$

${ }_{c} w_{c}$ : Direct exchange area when energy radiates from $w$ and arrives at $c$; meanwhile, $c$ is the only radiation source $\left(\mathrm{m}^{2}\right)$

${ }_{c} s_{c}$ : $\quad$ Direct exchange area when energy radiates from $s$ and arrives at $c$; meanwhile, $c$ is the only radiation source $\left(\mathrm{m}^{2}\right)$

${ }_{c} w_{w}$ : Direct exchange area when energy radiates from $w$ and arrives at $w$; meanwhile, $c$ is the only radiation source $\left(\mathrm{m}^{2}\right)$

\section{Angle Factors}

$X_{s, c}$ : Angle factor of the $s$ to $c$

$X_{s, w}$ : Angle factor of $s$ to $w$

$X_{w, s}$ : Angle factor of $w$ to $s$

$X_{c, w}$ : Angle factor of $c$ to $w$

$X_{w, c}$ : Angle factor of $w$ to $c$

\section{Emissivity and Absorptivity}

$\varepsilon: \quad$ Emissivity

$\alpha g$ : Absorptivity of $g$

$\alpha g s$ : Absorptivity of $g$ when the radiation energies derive from $s$

$\alpha g w$ : Absorptivity of $g$ when the radiation energies derive from $w$

agg: Absorptivity of gas when the radiation energies derive from $g$ itself

\section{Total Radiative Exchange Areas}

GS: Total radiative exchange area of $g$ to $s\left(\mathrm{~m}^{2}\right)$

$G W:$ Total radiative exchange area of $g$ to $w\left(\mathrm{~m}^{2}\right)$

GC: Total radiative exchange area of $g$ to $c\left(\mathrm{~m}^{2}\right)$

$S W: \quad$ Total radiative exchange area of $s$ to $w\left(\mathrm{~m}^{2}\right)$

SC: Total radiative exchange area of $s$ to $c\left(\mathrm{~m}^{2}\right)$

SG: $\quad$ Total radiative exchange area of $s$ to $g\left(\mathrm{~m}^{2}\right)$

WS: Total radiative exchange area of $w$ to $s\left(\mathrm{~m}^{2}\right)$

$W C$ : Total radiative exchange area of $w$ to $c\left(\mathrm{~m}^{2}\right)$

$W G$ : Total radiative exchange area of $w$ to $g\left(\mathrm{~m}^{2}\right)$

$W W$ : Total radiative exchange area of $w$ to $w\left(\mathrm{~m}^{2}\right)$

$C W$ : Total radiative exchange area of $c$ to $w\left(\mathrm{~m}^{2}\right)$

$C S: \quad$ total radiative exchange area of $c$ to $s\left(\mathrm{~m}^{2}\right)$

$C G$ : Total radiative exchange area of $c$ to $g\left(\mathrm{~m}^{2}\right)$

\section{Heat Flux}

${ }_{s} R_{s}: \quad$ Reflected heat flux when the radiation energies radiate from $s$ and arrive at $s\left(\mathrm{~W} / \mathrm{m}^{2}\right)$

${ }_{s} R_{w}$ : Reflected heat flux when the radiation energies radiate from the $s$ and arrive at $w\left(\mathrm{~W} / \mathrm{m}^{2}\right)$

${ }_{s} R_{c}$ : Reflected heat flux when the radiation energies radiate from $s$ and arrive at $c\left(\mathrm{~W} / \mathrm{m}^{2}\right)$

${ }_{w} R_{s}$ : Reflected heat flux when the radiation energies radiate from $w$ and arrive at $s\left(\mathrm{~W} / \mathrm{m}^{2}\right)$

${ }_{w} R_{w}$ : Reflected heat flux when the radiation energies radiate from $w$ and arrive at $w\left(\mathrm{~W} / \mathrm{m}^{2}\right)$

${ }_{w} R_{c}$ : Reflected heat flux when the radiation energies radiate from $w$ and arrive at $c\left(\mathrm{~W} / \mathrm{m}^{2}\right)$

${ }_{c} R_{s}$ : Reflected heat flux when the radiation energies radiate from $c$ and arrive at $s\left(\mathrm{~W} / \mathrm{m}^{2}\right)$

${ }_{c} R_{w}$ : reflected heat flux when the radiation energies radiate from $c$ and arrive at $w\left(\mathrm{~W} / \mathrm{m}^{2}\right)$

${ }_{c} R_{c}$ : Reflected heat flux when the radiation energies radiate from $c$ and arrive at $c\left(\mathrm{~W} / \mathrm{m}^{2}\right)$

${ }_{g} R_{s}$ : Reflected heat flux when the radiation energies radiate from $g$ and arrive at $s\left(\mathrm{~W} / \mathrm{m}^{2}\right)$

${ }_{g} R_{w}$ : Reflected heat flux when the radiation energies radiate from $g$ and arrive at $w\left(\mathrm{~W} / \mathrm{m}^{2}\right)$

${ }_{g} R_{c}$ : Reflected heat flux when the radiation energies radiate from $g$ and arrive at $c\left(\mathrm{~W} / \mathrm{m}^{2}\right)$.

\section{Data Availability}

The data used to support the findings of this study are included within the article.

\section{Conflicts of Interest}

The authors declare that they have no conflicts of interest.

\section{Acknowledgments}

This paper was supported by the National Key R\&D Plan of PR China (Project no. 2017YFB0304201) and the National Natural Science Foundation of PR China (project no. U1760115). 


\section{References}

[1] Z. Yi, W.-J. Zhang, Q.-D. Yang, G.-J. Li, and H.-G. Chen, "Influence analysis of the furnace wall emissivity on heating process," Infrared Physics \& Technology, vol. 93, pp. 326-334, 2018.

[2] S. H. Han and D. Chang, "Optimum residence time analysis for a walking beam type reheating furnace," International Journal of Heat and Mass Transfer, vol. 55, no. 15-16, pp. 4079-4087, 2012.

[3] S. J. D. Skeen and T. Gradworks, Oxygen-Enhanced Combustion: Theory and Applications, Dissertation, Washington University in St. Louis, St. Louis, MO, USA, 2009.

[4] P. Jiang and Q. Dong, "A new hybrid model based on an intelligent optimization algorithm and a data denoising method to make wind speed predication," Mathematical Problems in Engineering, vol. 2015, Article ID 714605, 16 pages, 2015.

[5] F. Zhang, T. Zirwes, H. Nawroth, P. Habisreuther, H. Bockhorn, and C. O. Paschereit, "Combustion-generated noise: an environment-related issue for future combustion systems," Energy Technology, vol. 5, no. 7, pp. 1045-1054, 2017.

[6] H. Mandova, W. F. Gale, A. Williams et al., "Global assessment of biomass suitability for ironmaking-opportunities for co-location of sustainable biomass, iron and steel production and supportive policies," Sustainable Energy Technologies and Assessments, vol. 27, pp. 23-39, 2018.

[7] M. Meng, W. Shang, D. Niu, and Q. Gao, "A new algorithm of parameter estimation for the logistic equation in modeling $\mathrm{CO}_{2}$ emissions from fossil fuel combustion," Mathematical Problems in Engineering, vol. 2014, Article ID 616312, 5 pages, 2014.

[8] W. Zhang, T. Wang, S. Zheng, X. Peng, and X. Wang, "Experimental study of the gas engine driven heat pump with engine heat recovery," Mathematical Problems in Engineering, vol. 2015, Article ID 417432, 10 pages, 2015.

[9] D. Johnson, R. Heltzel, and A. Nix, "Trends in unconventional well development-methane emissions associated with the use of dual fuel and dedicated," Natural Gas Engines, vol. 2, no. 12, pp. 988-995, 2015.

[10] A. Steinboeck, D. Wild, T. Kiefer, A. Kugi, and M. Transfer, “A mathematical model of a slab reheating furnace with radiative heat transfer and non-participating gaseous media," International Journal of Heat and Mass Transfer, vol. 53, no. 25-26, pp. 5933-5946, 2010.

[11] T. Morgado, P. J. Coelho, and P. Talukdar, "Assessment of uniform temperature assumption in zoning on the numerical simulation of a walking beam reheating furnace," Applied Thermal Engineering, vol. 76, pp. 496-508, 2015.

[12] S. H. Han, D. Chang, C. Y. Kim, and M. Transfer, "A numerical analysis of slab heating characteristics in a walking beam type reheating furnace," International Journal of Heat and Mass Transfer, vol. 53, no. 19-20, pp. 3855-3861, 2010.

[13] W.-J. Zhang, Z. Yi, and H.-G. Chen, "A new simplified zonal method for furnace thermal radiation calculation based on imaginary planes," Journal of Iron and Steel Research International, vol. 21, no. 4, pp. 419-426, 2014.

[14] A. Emadi, A. Saboonchi, M. Taheri, and S. Hassanpour, "Heating characteristics of billet in a walking hearth type reheating furnace," Applied Thermal Engineering, vol. 63, no. 1, pp. 396-405, 2014.

[15] J. G. Kim, K. Y. Huh, and I. T. Kim, “Three-dimensional analysis of the walking-beam-type slab reheating furnace in hot strip mills," Numerical Heat Transfer, Part A: Applications, vol. 38, pp. 589-609, 2000.

[16] M. Y. Kim, "A heat transfer model for the analysis of transient heating of the slab in a direct-fired walking beam type reheating furnace," International Journal of Heat and Mass Transfer, vol. 50, no. 19-20, pp. 3740-3748, 2007.

[17] F. Gliozzi, "The Stefan-Boltzmann law in a small box and the pressure deficit in hotSU(N) lattice gauge theory," Journal of Physics A: Mathematical and Theoretical, vol. 40, no. 19, pp. F375-F381, 2007.

[18] Y. Gim, W. Kim, B. Gwak et al., "On the effective StefanBoltzmann law and the thermodynamic origin of the initial radiation density in warm inflation," EPJ Web of Conferences, vol. 168, pp. 38-43, 2018.

[19] J. Chimal-Eguía, N. Sánchez-Salas, and M. Barranco-Jiménez, "A finite-time thermal cycle variational optimization with a Stefan-Boltzmann law for three different criteria," Entropy, vol. 14, no. 12, pp. 2611-2625, 2012.

[20] H. Chen, J. Ma, and H. Liu, "Least square spectral collocation method for nonlinear heat transfer in moving porous plate with convective and radiative boundary conditions," International Journal of Thermal Sciences, vol. 132, pp. 335-343, 2018.

[21] J. Ma, Y. Sun, and B. Li, "Spectral collocation method for transient thermal analysis of coupled conductive, convective and radiative heat transfer in the moving plate with temperature dependent properties and heat generation," International Journal of Heat and Mass Transfer, vol. 114, pp. 469-482, 2017.

[22] G.-J. Li and L.-Y. Wei, "Chebyshev collocation spectral method for radiative transfer in participating media with variable physical properties," Infrared Physics \& Technology, vol. 88, pp. 48-56, 2018.

[23] Z. Yi, Z. Su, G. Li, Q. Yang, and W. Zhang, "Development of a double model slab tracking control system for the continuous reheating furnace," International Journal of Heat and Mass Transfer, vol. 113, pp. 861-874, 2017.

[24] C.-T. Hsieh, M.-J. Huang, S.-T. Lee, and C.-H. Wang, "Numerical modeling of a walking-beam-type slab reheating furnace," Numerical Heat Transfer, Part A: Applications, vol. 53, no. 9, pp. 966-981, 2008.

[25] C.-T. Hsieh, M.-J. Huang, S.-T. Lee, and C.-H. Wang, "A numerical study of skid marks on the slabs in a walking-beam type slab reheating furnace," Numerical Heat Transfer, Part A: Applications, vol. 57, no. 1, pp. 1-17, 2010.

[26] J.-Y. Jang and J.-B. Huang, "Optimization of a slab heating pattern for minimum energy consumption in a walking-beam type reheating furnace," Applied Thermal Engineering, vol. 85, pp. 313-321, 2015.

[27] J. M. Casal, J. Porteiro, J. L. Míguez, and A. Vázquez, "New methodology for CFD three-dimensional simulation of a walking beam type reheating furnace in steady state," Applied Thermal Engineering, vol. 86, pp. 69-80, 2015.

[28] A. M. García and A. A. Amell, "A numerical analysis of the effect of heat recovery burners on the heat transfer and billet heating characteristics in a walking-beam type reheating furnace," International Journal of Heat and Mass Transfer, vol. 127, pp. 1208-1222, 2018.

[29] K. S. Chapman, S. Ramadhyani, and R. Viskanta, "Modeling and parametric studies of heat transfer in a direct-fired continuous reheating furnace," Metallurgical Transactions $B$, vol. 22, no. 4, pp. 513-521, 1991.

[30] C. Miao, H. G. Chen, and X.-W. Gao, "Mathematical models developed by zone method considering non-gray radiation 
properties of gas in combustion chamber," Journal of Iron and Steel Research International, vol. 17, no. 11, pp. 13-18, 2010.

[31] Z. Dan, D. Cang, H. Zhou, H. Bai, and Y. Zongg, "Microstructure and properties of high emissivity coatings," Journal of University of Science and Technology Beijing, Mineral, Metallurgy, Material, vol. 15, no. 5, pp. 627-632, 2008.

[32] J. Hellander, "How high emissivity ceramic coatings function advantageously in furnace applications," Materials \& Equipment/Whitewares: Ceramic Engineering and Science Proceedings, vol. 12, no. 1-2, pp. 162-169, 2008.

[33] Y. Sun, J. Ma, B. Li, and Z. Guo, "Predication of nonlinear heat transfer in a convective-radiative fin with temperature-dependent properties by the collocation spectral method," Numerical Heat Transfer, Part B: Fundamentals, vol. 69, no. 1, pp. 68-83, 2016.

[34] Y.-S. Sun, J. Ma, and B.-W. Li, "Spectral collocation method for convective-radiative transfer of a moving rod with variable thermal conductivity," International Journal of Thermal Sciences, vol. 90, pp. 187-196, 2015.

[35] M. Jing, Y. Sun, B. Li, and C. Hao, "Spectral collocation method for radiative-conductive porous fin with temperature dependent properties," Energy Conversion and Management, vol. 111, pp. 279-288, 2016.

[36] J. Ma, Y. Sun, and B. Li, "Simulation of combined conductive, convective and radiative heat transfer in moving irregular porous fins by spectral element method," International Journal of Thermal Sciences, vol. 118, pp. 475-487, 2017.

[37] J.-K. Zhang, B.-W. Li, H. Dong, X.-H. Luo, and H. Lin, "Analysis of magnetohydrodynamics (MHD) natural convection in $2 \mathrm{D}$ cavity and $3 \mathrm{D}$ cavity with thermal radiation effects," International Journal of Heat and Mass Transfer, vol. 112, pp. 216-223, 2017.

[38] M. Cui, X. Gao, and J. Zhang, "A new approach for the estimation of temperature-dependent thermal properties by solving transient inverse heat conduction problems," International Journal of Thermal Sciences, vol. 58, pp. 113-119, 2012.

[39] C. Miao, Z. Yi, B. Xu, and X.-W. Gao, "A new approach for determining damping factors in Levenberg-Marquardt algorithm for solving an inverse heat conduction problem," International Journal of Heat and Mass Transfer, vol. 107, pp. 747-754, 2017.

[40] C. Miao, W. W. Duan, and X.-W. Gao, “A new inverse analysis method based on a relaxation factor optimization technique for solving transient nonlinear inverse heat conduction problems," International Journal of Heat and Mass Transfer, vol. 90, pp. 491-498, 2015.

[41] M. F. Modest, "Radiative heat transfer," Journal of Heat Transfer, vol. 135, pp. 16-21, 2003.

[42] G.-J. Li, B.-W. Li, and Y.-S. Sun, "Extension of the reduced integration scheme to calculate the direct exchange areas in 3D rectangular enclosures with nonscattering media," Mathematical Problems in Engineering, vol. 2015, Article ID 703823, 11 pages, 2015.

[43] W. Zhou and T. Qiu, "Zone modeling of radiative heat transfer in industrial furnaces using adjusted Monte-Carlo integral method for direct exchange area calculation," Applied Thermal Engineering, vol. 81, pp. 161-167, 2015.

[44] H. Ebrahimi, A. Zamaniyan, J. S. Soltan Mohammadzadeh, and A. A. Khalili, "Zonal modeling of radiative heat transfer in industrial furnaces using simplified model for exchange area calculation," Applied Mathematical Modelling, vol. 37, no. 1617, pp. 8004-8015, 2013.
[45] F. Colangelo, G. De Luca, C. Ferone, and A. Mauro, "Experimental and numerical analysis of thermal and hygrometric characteristics of building structures employing recycled plastic aggregates and geopolymer concrete," Energies, vol. 6, no. 11, pp. 6077-6101, 2013. 